\title{
NUREG/CR-1488
}

Unlimited Release

\section{An Ultrasonic Thermometry System for Measuring Very High Temperatures in Reactor Safety Experiments}

Gary A. Carlson, William H. Sullivan,

Howard G. Plein, Thomas M. Kerley

Prepared by Sandia Laboratóries. Albuquerque, New Mexico 87185

and Livermore, California 94550 for the United States Department

of Energy under Contract DE.AC04-76DP00789

Printed June 1979

DO NOT MICROFILM

COVER

\section{Sandia Laboratories}




\section{DISCLAIMER}

This report was prepared as an account of work sponsored by an agency of the United States Government. Neither the United States Government nor any agency Thereof, nor any of their employees, makes any warranty, express or implied, or assumes any legal liability or responsibility for the accuracy, completeness, or usefulness of any information, apparatus, product, or process disclosed, or represents that its use would not infringe privately owned rights. Reference herein to any specific commercial product, process, or service by trade name, trademark, manufacturer, or otherwise does not necessarily constitute or imply its endorsement, recommendation, or favoring by the United States Government or any agency thereof. The views and opinions of authors expressed herein do not necessarily state or reflect those of the United States Government or any agency thereof. 


\section{DISCLAIMER}

Portions of this document may be illegible in electronic image products. Images are produced from the best available original document. 
Issued by Sandia Laboratories, operated for the United States Department of Energy by Sandia Corporation.

\section{NOTICE}

This report was prepared as an account of work sponsored by the United States Government. Neither the United States nor the Department of Energy, nor any of their employees, nor any of their contractors, subcontractors, or their employees, makes any warranty, express or implied, or assumes any legal liability or responsibility for the accuracy, completeness or usefulness of any information, apparatus, product or process disclosed, or represents that its use would not infringe privately owned rights.

\section{DO NOT MILTIURILM
COVER}




\title{
NUREG/CR-1488
}

\author{
AN ULTRASONIC THERMOMETRY SYSTEM FOR MEASURING
}

\section{VERY HIGH TEMPERATURES IN REACTOR SAFETY EXPERIMENTS}

G. A. Carlson, W. H. Sullivan, H. G. Plein ${ }^{\star}$ and T. M. Kerley

Sandia Laboratories, Albuquerque, NM 87185

\begin{abstract}
Ultrasonic thermometry has many potential applications in reactor safety experiments, where extremely high temperatures and lack of visual access may preclude the use of conventional diagnostics. This report details ultrasonic thermometry requirements for one such experiment, the molten fuel pool experiment. Sensors, transducers, and signal processing electronics are described in detail. Axial heat transfer in the sensors i.s modelled and found acceptably small. Measurement errors, calculations of their effect, and ways to minimize them are given. A rotating sensor concept is aiscussed which holds promise of alleviating sticking problems at high temperature. Applications of ultrasonic thermometry to three in-core experiments are described. In them, five 10-mm-length sensor elements were used to measure axial temperatures in a $\mathrm{UO}_{2}$ or $\mathrm{UO}_{2}$-steel system fission-heated to about $2860^{\circ} \mathrm{C}$.

\section{DISCLAIMER}

This report was prepared as an account of work sponsored by an agency of the United Statcs Government. Neither the United States Government. nnr any agency thereof, nor any of their employees, makes any warranty, express or implied, or assumes any legal liability or responsibility for the accuracy, completeness, or usefulness of any information, apparatus, product, or process disclosed, or represents that its use would not infringe privately owned rights. Reference herein to any specific commercial product, provess, or service by trade name, trademark, manufacturer, or otherwise does not necessarily constitute or imply its endorsement, recommendation, or favoring by the United States Government or any agency thereof. The views and opinions of authors expressed herein do not necessarily state or reflect those of the Unitod States Government nr any agency thereof.
DISTRIBUTION OF THS DOCUMENT IS UHLIMITEO

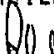

Deceased 
Table of Contents

Page

1. INTRODUCTION . . . . . . . . . . . . . . . 1

2. THEORY AND PREVIOUS APPLICATIONS . . . . . . . . 3

3. ULTRASONIC THERMOMETRY REQUIREMENTS

AND DEVELOPMENTS . . . . . . . . . . . . . . . 6

a. Sensor Requirements . . . . . . . . . 6

b. Signal Transducers . . . . . . . . . . . . 6

c. Signal Processing Electronics . . . . . . . . 7

d. Magnetostrictive Wire Requirements . . . . . y

e. Sensor Wire Requirements... . . . . . . . . 11

f. Sheath Materials . . . . . . . . . . . . 12

g. Reflective Discontinuities on Sensor Wire . . 13

h. Ultrasonic Thermometry Laboratory

Experiments ............... . 16

i. Axial Heat Transfer in Sensor Wires . . . . . 18

j. Ultrasonic Thermometry Measurement Errors . . 19

k. Rotating Sensor Concept ......... 24

4. APPLICATIONS OF ULTRAGONIC TIERMOMETRY

IN REACTOR EXPERIMENTS . . . . . . . . . • • 25

5. CONCLUSIONS . . . . . . . . . . . . . . . 31

Appendix A -- Signal Processing Electronics . . . . 32

Appendix B -- Evaluating the Effect of Overlapping

Signals on the Accuracy of UItrasonic

Thermometry Data........... 43

6. REFERENCES ................. 54 


\title{
AN ULTRASONIC THERMOMETRY SYSTEM FOR MEASURING
}

\author{
VERY HIGH TEMPERATURES IN REACTOR SAFETY EXPERIMENTS
}

G. A. Carlson, W. H. Sullivan, H. G. Plein* and T. M. Kerley Sandia Laboratories, Albuquerque, NM 87185

\begin{abstract}
Ultrasonic thermometry has many potential applications in reactor safety experiments, where extremely high temperatures and lark of visual access may preclude the use of conventional diagnostics. This report details ultrasonic thermometry requirements for one such experiment, the molten fuel pool experiment. Sensors, transducers, and signal processing electronics are described in detail. Axial heat transfer in the sensors is modelled and found acceptably small. Measurement errors, calculations of their effect, and ways to minimize them are given. A rotating sensor concept is discussed which holds promise of alleviating sticking problems at high temperature. Applications of ultrasonic thermometry to three in-core experiments are described. In them, five lo-mm-length sensor elements were used to measure axial temperatures in a $\mathrm{UO}_{2}$ or $\mathrm{UO}_{2}$-steel system fission-heated to about $2860^{\circ} \mathrm{C}$.
\end{abstract}

\section{INTRODUCTION}

A critical diagnostic measurement in many reactor safety experiments is temperature. Besides being important to a general understanding of the course of experiments, temperature data are often required for the determination of heat fluxes. Unfortunately, the temperatures to be measured are often beyond the useful range of thermocouples $\left(\sim 2200^{\circ} \mathrm{C}\right.$ for sheathed tungstenrhenium alloy couples, due to insulator shunting effects).l Pyrometric measurements are often inadequate due to a lack of optical access or to interference by intervening vapors or aerosols. One method which has been used with some success 
in the past for measurements of very high temperatures (to $2600^{\circ} \mathrm{C}$ ) in reactor experiments is ultrasonic thermometry. ${ }^{2-4}$ Ultrasonic thermometry exploits the temperature dependence of acoustic velocity that all materials exhibit. By measuring the time required for an acoustic signal to propagate between two points in a well-characterized material, the temperature of that segment of material can be determined.

This report describes the development of an ultrasonic thermometer for use in the sandia LMFBR safety research program. Applications to date have been in the Molten Fuel Pool study, but applications to Debris $B^{5} d^{5}$ experiments are planned. Details of the sensor construction are given, and the electronics system for data acquisition and analysis is described fully, with circuit diagrams provided. Laboratory studies of the system are discussed, and calibration data shown. The first applications of the system to in-reactor temperature measurements are described. Potential problems of ultrasonic thermometry, including the effects of multiple reflections on measurement accuracy; are evaluated and recommendations made. Finally, future plans for application of the technique are given. 


\section{THEORY AND PREVIOUS AFPLICATIONS}

Although the temperature dependence of acoustic velocity of gases or liquids could be and sometimes is used in temperature measurements, the present study will consider only the use of solid metal wires as sensors. The acoustic velocity in a solid is given by $v=(M / \rho)^{\frac{1}{2}}$, in which $M$ is a modulus of the material and $\rho$ is the density. Since the modulus and the density in a solid are temperature-dependent, the acoustic velocity can be used as a measure of temperature. For solids, both shear and compressional waves can be transmitted, and either shear or compressional waves can be used for temperature measurements. In practice, extensional (compressional) waves in a smalldiameter metal wire have generally been employed, for which $v=(E / \rho)^{\frac{1}{2}}, E$ being Young's modulus.

Figure 1 illustrates schematically a thin-wire ultrasonic thermometer. A short-duration acoustic pulse is generated in a magnetostrictive* wire by a pulsed magnetic field produced by an exciting coil. The acoustic pulse propagates down this wire and into an attached sensor wire, which has a number of acoustic discontinuities near the end. In the example shown, the diameter change and the end of the wire are the acoustic discontinuities. A part of the acoustic pulse energy is reflected from each discontinuity, and is reacquired by the exciting coil as an electrical signal by the inverse of the pulse generating process. Because the velocity of the acoustic pulse is a function of

\footnotetext{
* A magnetostrictive wire undergoes a change in length under an applied magnetic field. Magnetostrictive materials include nickel, remendur and elinvar.
} 
the temperature in the sensor wire, the difference in arrival times for reflections from adjacent discontinuities can be related to the average temperature of the wire between those discontinuities.

Since a number of acoustic discontinuities can be provided on a given sensor wire, a temperature profile along that wire can be measured. 7 This is one of the primary attractions of the ultrasonic thermometry technique. However, the principal advantage of this technique over more conventional methods is that it can be used at very high temperatures, limited in theory only by the melting point of the sensor material. For tungsten alloy sensors which have been employed, this temperature limitation is $3410^{\circ} \mathrm{C}$, more than $1000^{\circ} \mathrm{C}$ higher than measurable with sheathed thermocouples.

The ultrasonic thermometry technique has been employed by a number of investigators ${ }^{2-4}$ to measure the centerline temperatures of nuclear reactor fuel pins. Temperatures around $2400^{\circ} \mathrm{C}$ have been measured, for periods of several hundred hours: All these studies have employed tungsten or tungsten alloy sensors in tungsten alloy sheaths. The results of these studies have been only partially satisfactory. Arave and co-workers ${ }^{3}$ measured temperatures to $2000^{\circ} \mathrm{C}$ for six days, but found "sticking" problems (sticking is the contact welding of metallic sensor to metallic sheath at high temperatures, which causes spurious reflections and temperature measurement errors) resulting in a $300^{\circ} \mathrm{C}$ calibration error. At higher temperatures $\left(2700^{\circ} \mathrm{C}\right)$, the transmission line sheath collapsed aftér two hours, masking 
the sensor signal. Tasman et al. 4 measured temperatures above $2300^{\circ} \mathrm{C}$ for over 300 hours, using two ultrasonic thermometers inserted in either end of a fuel pin. One of the thermometers failed after 14 hours due to sticking, and the other developed sticking interferences intermittently, which were cured in each case by temperature cycling the reactor (and hence the fuel pins and thermometers).

Due to the "sticking" problem, the full potential of ultrasonic thermometry was not realized in either of these studies. Although some data were obtained at higher temperatures than could have been reliably measured with thermocouples, the technique still awaits more satisfactory treatment of the sticking problem. This problem will be discussed in some detail in this report. 


\section{ULTRASONIC THERMOMETRY REQUIREMENTS AND DEVELOPMENTS}

\section{3a. Sensor Requirements}

For one of the LMFBR safety studies, being conducted at Sandia for the Nuclear Regulatory Commission (the Molten Fuel Pool study), it was desired to measure temperatures and temperature gradients in $\mathrm{UO}_{2}$ to its melting point $\left(2860^{\circ} \mathrm{C}\right)$ or above. The only method of temperature measurement which appeared to be applicable to this problem was ultrasonic thermometry. Since no commercial equipment existed which could be used for such measurements, * a development program was initiated:

In general, the applications made of thin-wire ultrasonic thermometry in the past ${ }^{2-4}$ had involved relatively long ( $50 \mathrm{~mm}$ ) sensor elements, and coils and electronics appropriate for sensors of this length. For our applications, it was desired to have sensor elements no longer than $10 \mathrm{~mm}$, since the entire height of the temperature zone to be measured was $50 \mathrm{~mm}$ and considerable temperature gradients were expected. To develop a system suitable for $10 \mathrm{~mm}$ sensor elements, all aspects of previous ultrasonic thermometry systems had to be evaluated and most of them changed. Technology developed a number of years ago for use in acoustic delay 1 ines $^{8}$ was quite helpful in this development.

\section{3b. Signal Transducers}

A $10 \mathrm{~mm}$ length sensor element of thoriated tungsten results in reflected acoustic signals about $4 \mathrm{\mu s}$ apart. To insure adequate

\footnotetext{
* A commercial unit has been marketed for several years by Panametrics, Inc. However, it did not have the temporal or spatial resolution required for the present application.
} 
signal separation, the acoustic pulse then should be no longer than 2-3 us (see Fig. 2). At the same time, shorter pulses are not desirable, since they result in lower signal amplitude. The acoustic pulse length is determined by the length of magnetostrictive wire coupled by the pulsed magnetic field, combined with the time duration of the magnetic field pulse. ${ }^{\star}$ To minimize the length of magnetostrictive wire coupled by the pulsed maqnetic field, short ( $2 \mathrm{~mm}$ length) pulse coils were employed. Ferrite discs at the ends of the coil further restricted the axial extent of the magnetic field lines to about $4 \mathrm{~mm}$. To optimize the duration of the pulse, relatively low-inductance pulse coils were used, together with a low impedence current pulse driver (described later). Coils which gave satisfactory results had 100-150 turns of \#44 copper wire, wound on a Delrin bobbin $2 \mathrm{~mm}$ long and $1.1 \mathrm{~mm}$ in diamëter. The inductance of satisfactory coils ranged from 15 to $30 \mu \mathrm{H}$. The use of the ferrite discs was actually not necessary

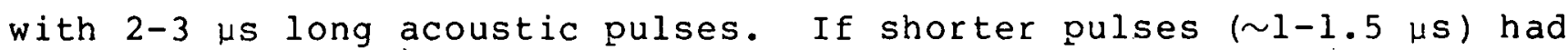
been required, signal improvement with $0.5 \mathrm{~mm}$ thick ferrites at each end of the coil would have been been much more obvious.

\section{3c. Signal Processing Electronics}

The signal processing electronics are described in detail in Appendix A. Here only a brief summary of the electronics will be given. Initially, a charged cable pulser is used to produce a short duration, high amplitude current pulse in the pulse coil. After a time delay, the returned acoustical signals reflected from

* See Ref. 9 for a more complete description of the pulse length and chapc obtained from a magnetostrictive transducer. 
the sensor elements induce new electicical signals in the same pulse coil. These signals are run through a line driver amplifier for transmission to a remote signal processing console. Here; the signals are further amplified and hard limited to give a TTL-compatible series of logic transitions corresponding to signal. zero-crossings. After isolating an appropriate set of zerocrossings using tracking gate control servos, the average time delay between reflected signals for a given sensor element is measured, using a commercial timer. Normally, 100 measurements of the delay time for a given sensor element are averaged, to provide the necessary time resolution (better than $10 \mathrm{~ns}$ ). The time resolution is otherwise limited by the relatively slow clock frequency of the counter $(10 \mathrm{MHz})$ rather than by jitter in the zero-crossing signals. A multiplexing system is used to allow sequential measurement of as many as 10 sensor elements ( 5 elements on each of two sensors). A pulser frequency of $60 \mathrm{~Hz}$ provides an averaged delay time measurement every. $1.67 \mathrm{~s}$, or $16.7 \mathrm{~s}$ for a complete sequence of 10 delay time-hence, temperature-measurements.

\section{3d. Magnetostrictive Wire Requirements}

The optimal magnetostrictive wire diameter aepends on the characteristics of the exciting pulse and of the resulting acoustic pulse. If the wire diameter is too large, then dispersion of the acoustic wave results, and the wave shape and amplitude are changed. On the other hand, if the diameter, is too small, there is inadequate coupling of the wire with the pulsed magnetic field and the amplitude of the signals drops. For the present 
case, the optimal wire diameter for the remendur magnetostrictive material was about $0.7 \mathrm{~mm}$.

Remendur was one of several magnetostrictive materials which could have been used for this application. It was chosen because it has a high magnetostrictive coefficient, and it has been successfully used by most other ultrasonic thermometry investigators. To obtain the maximum magnetostrictive effect (determined by the ratio of electrical signal returned to input electrical signal), it is necessary to heat-treat the remendur before use, and also to apply a DC magnetic field to the wire during use. The heat treatment recommended by the manufacturer to develop the maximum magnetic properties requires several hours at various temperatures in a protected atmosphere. However, in the present studies, a simple short-duration heating to a very dull réd heat (barely visible) with a torch gave quite satisfactory signal amplitude.

Biasing the remendur with a DC magnetic field is necessary because the magnetostrictive effect is quadratic with magnetic field strength. However, there is a maximum effective DC field strength beyond which signal amplitude actually declines. For the present application, simple Alnico rod magnets, $5 \mathrm{~mm}$ diameter dud $25 \mathrm{~mm}$ long, gave maximum aignal amplitudes when used in close proximity $(3-5 \mathrm{~mm})$ to the remendur wire.

The length of the magnetostrictive wire used is not critical. However, since there may be a small impedance mismatch at the tungsten-remendux junction (typically log reflected signal amplitude for a butt-welded joint), the length of remendur should 
be chosen to prevent interference of any joint reflection with the reflected signals from the sensor. This required making the acoustical propagation time through the remendur section either shorter or longer than that between any two sensor element reflections (see section $3 j$ for details on interference which may otherwise result).

To obtain a longer propagation time in the remendur, the acoustic delay between the two furthest separated sensor reflections at the highest use temperature must be exceeded. Considering the room temperature acoustic velocity of remendur $(5400 \mathrm{~m} / \mathrm{s})$, and the acoustic velocity of thoriated tungsten at $3000^{\circ} \mathrm{C}(3300 \mathrm{~m} / \mathrm{s})$, the physical length of remendur must be more than 1.64 times the length of the tungsten sensor element section to insure no reflection interference $(>82 \mathrm{~mm}$ in the present case, for five $10 \mathrm{~mm}$ sensör elements).

Alternatively, the remendur section could be made shorter acoustically than the shortest delay between sensor, element reflections at the lowest use temperature. Assuming a $10 \mathrm{~mm}$. distance between sensor reflective discontinuițies and room temperature as the lowest use temperature, the length of remendur would need to be less than $10 \times 5400 / 4320=12.5 \mathrm{~mm}$. In fact, the length would necessarily be several $\mathrm{mm}$ less than this to insure no overlap of reflected signals. However, the signal amplitude decreases as the remendur is shortened due to the decreased coupling with the pulsed and steady magnetic fields. Figure 3 shows the signal amplitude received as a function of remendur length. As shown, a reduction of signal of about a 
factor of 3 may result. from use of a sufficiently short remendur section. For this reason, it may be more desirable to use a long remendur section rather than a short one.

3e. Sensor Wire Requirements

There are two principal considerations in the choice of a sensor material for any application. First, the sensor material must be chemically and physically stable in the environment and at the temperatures of interest. If several materials meet this criterion, then a second consideration is the temperature sensitivity of the sensor materials.

For the present application, in which temperatures to near $3000^{\circ} \mathrm{C}$ are to be measured, the choice of sensor materials is limited to a few very refractory metals and alloys. of these, tantalum is highly oxidation-sensitive and would not be stable in the $\mathrm{UO}_{2}$ environment. Rhenium has a high temperature sensitivity, but is 1 imited to temperatures below $2600^{\circ} \mathrm{C}$. Pure tungsten. (and probably tungsten-rhenium alloys) tends to recrystallize with time at temperature, resulting in changing moduli, increasing signal attenuation, and varying calibration curves. The best sensor material for these applications appears to be thoriated tungsten. 4 Although its sensitivity is not as great as some of the other metals, thoriated tungsten has a very stable calibration curve after an initial heat treatment, due to grain boundary pinning by the $\mathrm{ThO}_{2}$. This material has been chosen for use by others 4,11 and is presently being used in our studies. 
The diameter of thoriated tungsten wire required for impedance matching to $0.7 \mathrm{~mm}$ remendur is near $0.5 \mathrm{~mm}$, a readily available size. Percussive-arc welding (butt-welds) was a convenient means of attaching the remendur and tungsten. A strong though somewhat brittle joint was obtained in this way.

\section{3f. Sheath Materials}

When the sensor is used in an environment such as sintering and melting $\mathrm{UO}_{2}$, it is necessary to separate the sensor from the $\mathrm{UO}_{2}$ to prevent interfering acoustic signals at points of contact. This has generally been accomplished ${ }^{2-4}$ with a protective sheath of a tungsten-rhenium alloy (thoriated tungsten sheaths could not be readily fabricated). However, there is a strong tendency for the sheath and the sensor to contact weld above $1800^{\circ} \mathrm{C}$, resulting in the same type of an acoustic interference that the sheath was meant to prevent. This has sometimes been reducedll by using standoffs at intervals on the sensor wire to localize and minimize the contact area. However, for the present application it. was judged that the reflections from the standoffs themselves were excessive, so this technique was not applied. Instead, an

* The impedance for extensional waves is $Z^{\prime}=\rho \nu^{A}$; in which $\rho$ is the density, $v_{e}$ the extensipgal wave velocity and A the crosssectional area of the wire.12. For impedance matching, ${ }_{1} / Z_{2}=1=\frac{\rho_{1} \nu_{1}^{A} 1}{\rho_{2}{ }_{2} A_{2}}$. For tungsten and remendur, this requires $\frac{A_{W}}{A_{R}}=\frac{\rho_{R}{ }^{\nu} R}{\rho_{T_{N}}{ }^{\nu} W}=\frac{(8.2)(5400)}{(19.3)(4320)}=0.53$ giving $d_{W_{N}} / a_{R}=0.73$ as the wire diameter ratio. 
alternative sheath material, $\mathrm{ThO}_{2}$, was found which did not stick to the sensor wire. This minimized interfering reflections (minor reflections will still occur if either the sensor or the sheath is curved or bent so that significant contact occurs). The $\mathrm{ThO}_{2}$ sheaths work quite well for experiments of short duration. For longer experiments ( 60 minutes) at high temperatures $\left(2800-2900^{\circ} \mathrm{C}\right)$ the vapor pressure of $\mathrm{ThC}_{2}$ is sufficiently high that $\mathrm{ThO}_{2}$ vaporized from hot portions of the sheath may condense on a cooler portion of the sensor and cause new reflections which may affect the temperature measurements. It is also possible that slow chemical interactions between tungsten and $\mathrm{ThO}_{2}$ could occur, changing the sensor calibration. However, this effect was not observed in furnace experiments up to one hour in duration.

\section{3g. Reflective Discontinuities on Sensor Wire}

A variety of acoustic reflective discontinuities can be used to define the ends of the sensor elements. Step changes in wire diameter can be used to cause an impedance mismatch with readily defined reflection and transmission coefflcients. ${ }^{12}$

$$
\begin{aligned}
& \mathrm{R}=\frac{\mathrm{z}_{2}-\mathrm{z}_{1}}{\mathrm{z}_{2}+\mathrm{z}_{1}} \\
& \mathrm{~T}=\frac{2 \mathrm{z}_{2}}{\mathrm{z}_{2}+\mathrm{z}_{\perp}}
\end{aligned}
$$

Here, $Z_{1}$ and $Z_{2}$ are the impedances of the sensor wire before and after the step diameter change, and are related by 


$$
\frac{z_{1}}{z_{2}}=\frac{a_{1}{ }^{2}}{a_{2}{ }^{2}}
$$

where $d_{1}$ is the initial wire diameter and $d_{2}$ is the changed wire diameter. Thus the reflection coefficient is

$$
R=\frac{d_{2}^{2}-d_{1}^{2}}{d_{2}^{2}+d_{1}^{2}}
$$

and the diameter ratio required to give a specific reflection coefficient,

$$
\frac{\mathrm{d}_{2}}{\mathrm{~d}_{1}}=\left(\frac{1+\mathrm{R}}{1-\mathrm{R}}\right)^{\frac{1}{2}}
$$

Other types of reflective discontinuities, while not readily. treated mathematically, nevertheless produce quite acceptable reflections. These include notches, loops and standoffs. Loops and standoffs would appear to serve a double function of providing a reflective discontinuity and at the same time minimizing contact between sensor and sheath. However, the reflection at a loop or standoff can be modified not only in amplitude but in shape by contact with the sheath. Since the measurement of temperature by ultrasonic thermometry depends on very accurate measurement of the time between successive reflections, irreproducible changes in shape of a reflected signal cannot be tolerated. For this reason, loops and standoffs have not generally been used as discontinuities. Notches, on the other hand, are well suited to this application. They have been employed in the present study, primarily because they are more easily obtained than step diameter 
changes of extended length. The notches used in this work consisted of circumferential cuts in the wire produced by a thinbladed $(0.4 \mathrm{~mm})$ diamond wheel. Neither the width nor the shape of the notches is believed to have a significant effect on the pulse shape, since the cuts are very short compared to the acoustical pulse (reflected signal amplitude, however, may be affected). Figure 4 illustrates the depth of notches required to obtain various reflection coefficients, compared to the depth of step diameter changes. Interestingly, the notch depth/signal ratio curve has the same slope as, but is displaced from, the curve for a signal reflected following two successive diameter changes. This is perhaps not surprising, since a notch represents a double diameter change with a very short distance between steps. The acoustical energy in a pulse is related to the square of the pressure amplitude, so that the reflected and transmitted energies, are given by

$$
\begin{aligned}
& E_{R}=E_{O} R^{2} \\
& E_{T}=E_{O}\left(1-R^{2}\right)
\end{aligned}
$$

with $R$ the pressure amplitude reflection coefficient. 12 Thus for example, a reflection whose amplitude is 208 of the initial amplitude only removes 4 of of the acoustic energy, and a number of $20 \%$ reflections will cause relatively minor degradation of the signal amplitude. In the present studies, Eive reflective discontinuities at 9-10 mm intervals, with reflection coefficients between 0.2 and 0.3 , were typically used, along with the end reflection, to define five sensor elements. 
3h. Ultrasonic Thermometry Laboratory Experiments

Experiments to characterize ultrasonic thermometry behavior were $r$ un in an inert-gas-filled, tungsten mesh-heated furnace, which provided temperatures to $2900^{\circ} \mathrm{C}$. In general, the thermometers were suspended vertically in the heated zone, and had limited contact with other materials. In early experiments, the thermometers did experience some contact with tungsten or molybdenum heat shields at the top of the heated zone (right-angle contact between the horizontal shields and the vertical sensor) which resulted in some sticking (welding) at temperatures above $2000^{\circ} \mathrm{C}$. This problem was largely alleviated by providing a $\mathrm{ThO}_{2}$ sheath around the sensor over the length which passed through the shields into the heated zones. Normally, the $\mathrm{ThO}_{2}$ sheath did not extend far beyond the heat shields into the heated zone unless it was desired specifically" to look at sheath-sensor interactions.

The sensor wires used were $2 \%$ thoriated tungsten, specified as "straight rod" by the manufacturer.* Calibrations were performed on roughly $220-\mathrm{mm}-1$ ong sensor wires, silver-soldered or

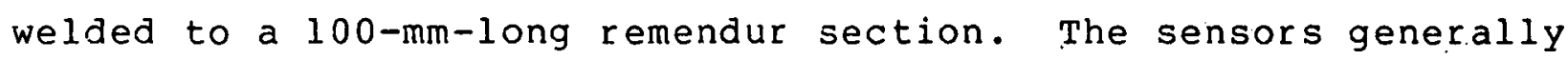
had 5 sensor elements of 9-10 mm length, plus an additional 25$50 \mathrm{~mm}$ of sensor wire, in the heated zone of the furnace. This insured relatively constant temperature in the calibrated section of wire. Calibration of the sensor elements normally involved measuring the delay time at different temperatures between each pair of reflections including the pair with the end reflection. Thus five calibration curves were obtained

*Kulite Semiconductor Products, Inc. 
for a given sensor wire. In the heated zone, sensors were surrounded by a thin-wall tungsten tube, providing a quasi-blackbody enclosure. Temperatures were measured using a manual optical pyrometer sighted on a small hole in the tungsten tube, providing measurements with an accuracy of $15^{\circ} \mathrm{C}$ above $2000^{\circ} \mathrm{C}$. Calibration curves for adjacent sensor elements varied slightly, apparently due to variations in wire composition or grain structure.

Figure 5 shows signals obtained from one sensor element at different temperatures, using a 150 turn pulse coil, and $10 \mathrm{~m}$ of RG-58 cable between the pulser and the coil (see Appendix A). The signal has been amplified in the pulser circuitry. A typical. calibration curve for a single sensor element is shown in Figure 6 . The acoustic velocity as a function of temperature for the first heating cycle (not shown) is quite different from subsequent heating cycles, indicating some permanent change in the internal structure of the thoriated tungsten wire. After the initial heating the temperature-delay time curve is quite reproducible. Calibration curves were fit using a fifth-order polynomial. Best results were obtained when the curve was broken into a lowand a high-temperature segment, due to the marked change in slope at higher temperatures. The standard deviation of the high-temperature segments $\left(1400^{\circ} \mathrm{C}\right.$ to $\left.2850^{\circ} \mathrm{C}\right)$ was typically near $\pm 10^{\circ} \mathrm{C}$. The accuracy of the calibration data was limited by the accuracy of the optical pyrometer measurements to $\pm 15^{\circ} \mathrm{C}$ above $1800^{\circ} \mathrm{C}$.

At temperatures above $1800^{\circ} \mathrm{C}$, some attenuation of the reflected signals was observed. Figure 7 shows the attenuation at different temperatures for a signal from a 2 -thoriated tungsten 
ultrasonic thermometer, reflected from a point $80 \mathrm{~mm}$ into the high temperature zone. For applications where a significant length of sensor wire must be in a high temperature zone, attenuation could be a problem.

3i. Axial Heat Transfer in Sensor Wires

In the first application planned for the ultrasonic thermometers, measurement of temperatures in fission-heated $\mathrm{JO}_{2}$, there was concern that significant temperature measurement errors might result from axial thermal conductivity in the sensor wire, because the thermal conductivity of the tungsten sensors was much higher than that of granular $\mathrm{UO}_{2}(1 \mathrm{~W} / \mathrm{cmK}$ vs. $0.015 \mathrm{~W} / \mathrm{cmK})$. Computer modeling of the expected transient heating and cooling cycle was attempted, but failed due to stability problems. Subsequentily, a steady-state model was used to establish an upper bound on the measurement error.13 The configuration of tungsten sensor and sheath and $\mathrm{UO}_{2}$ fuel sample initiály modeled are shown in Figure 8. A volumetric heating rate was chosen, which gave the predicted axial and radial temperature gradients in the fuel using an isothermal outer boundary. Temperature profiles "were calculated with and without the sensor and sheath present in the fuel. The presence of the sensor and sheath depressed the $\mathrm{UO}_{2}$ temperature as much as $42^{\circ} \mathrm{C}$. Similar calculations performed using a $\mathrm{ThO}_{2}$ sheath in place of the tungsten sheath; with the same imposed temperature gradient, indicated a maximum temperature measurement error of $20^{\circ} \mathrm{C}$, due to the much lower thermal conductivity of $\mathrm{ThO}_{2}$ relative to tungsten. Results of the calculations with a $\mathrm{ThO}_{2}$ sheath are shown in Figure 9. 
The calculated volumetric heating rates necessary to produce the desired temperature gradients in the $\mathrm{UO}_{2}$ at steady state were 2-4 times lower than the actual experimental heating $r a t e s, 14$ demonstrating the departure of the experiment from a steady-state condition, and also suggesting a lower temperature error in the actual experiment than calculated. Further, the temperature gradients actually observed in the experiments with $\mathrm{UO}_{2}{ }^{14}$ were more than a factor of two lower than used in these calculations. Assuming the temperature error declines roughly in proportion to the axial temperature gradient (other calculations indicated this to be a reasonable assumption), it appears that temperature measurement errors of less than $20^{\circ} \mathrm{C}$ (tungsten sheath) or $10^{\circ} \mathrm{C}\left(\mathrm{ThO}_{2}\right.$ sheath) can be anticipated for the sensors used in the experiments to be described.

\section{3j. Ultrasonic Thermometry Measurement Errors}

Although the calibration curves generated in furnace experiments suggest a temperature measurement capability limited only by the accuracy of pyrometric temperature measurements, a numbcr of temperature measurement errors can occur with ultrasonic thermometers in less ideal measurement situations. Differences between the temperature of the sensor and its surroundings due to axial heat losses in the sensor have been treated in the preceeding section and found to be generally small and within the measurement uncertainty. Two other sources of error are somewhat harder to define, but potentially can be very troublesome.

The first is the effect of overlap of multiple reflections among the sensors with the primary sensor reflections. This 
area is discussed in detail in Appendix 'B. The results of an analysis of this problem are that for reflection coefficients of the sensor elements of 0.20 or less, the temperature errors resulting from multiple reflections are likely to be within the measurement uncertainty. For larger sensor reflection coefficients, the errors resulting from multiple reflections may become prohibitively high for certain sensor elements (not all sensor elements are equally susceptible to this problem). In the present studies, an attempt was made to keep the reflection coefficients near 0.20 to maximize signal amplitude without seriously affecting measurement accuracy.

The second source of measurement error is caused by spurious reflections due to some unwanted contact between the sensor for remendur) and surrounding materials. For example, if the sensor enters a sealed vessel, it must pass through, and contact, some type of seal. A reflection of some magnitude will be developed at the point of contact. Additionally, the sensor and the sheath are likely to be in contact at one or several points, causing reflections.. There will also be a reflection at the remendurtungsten weld, as discussed previously. If these reflections are sufficiently small, then they will not affect temperature measurements perceptibly. However, if the reflections become large enough and occur in the wrong. places, they can cause substantial errors in the temperatures measured.

As an example, Figure 10 shows a sensor with a number of reflection points $(7-10)$ in addition to the desired sensor element reflection points $(1-6)$. The desired signals will traverse 
paths 10-1-10, 10-2-10, etc. However, multiple signal reflection paths such as 10-1-10-9-10 and many other combinations are also possible. If the acoustic distance from 10 to 9 is nearly the same as that from 1 to 5 , then the multiple reflection signal 10-1-10-9-10 will overlap the desired signal 10-5-10. Since reflections 1 and 5 are of the same magnitude, and reflection 10 is essentially a total reflection, then a $20 \%$ reflection coefficient for reflection 9 will cause an interfering reflection from 10-1-10-9-10 which is 20\% of the amplitude of the primary 10-5-10 reflection. Calculations based on the equations given in Appendix $B$, assuming a $10 \mathrm{~mm}$ length sensor element and a $500 \mathrm{kHz}$ signal center frequency, show that the maximum effect of such an interfering signal would be to shift the primary waveform by $65 \mathrm{~ns}$, which could result in a temperature error of from 100 to $400^{\circ} \mathrm{C}$, depending on the temperature sensitivity of the sensor at the temperature being measured.

Many other multiple reflections involving undesired reflection points could contribute to temperature errors. For example, a strong reflection developed at a sheath-sensor contact prior to sensor elements (7a) could cause interfering multiple reflections as well as primary signal attenuation. Alternatively, the sheath-sensor contact point could be somewhere within the sensor elements (7b). The interference may not be obvious from an inspection of the signal waveforms. However, as previously stated rather sinall temporal shifts can cause large apparent temperature errors $\left(1.4-6^{\circ} \mathrm{C} / \mathrm{ns}\right.$ in the present case). 
From the above it is apparent that to insure accurate temperature measurements using short sensor elements, it is important to minimize unnecessary reflections or to constrain them to occur at locations where they will not overlap the sensor element signals. The feedthrough and weld reflections can be made reasonably small ( $10 \%)$, but are most easily dealt with by making the acoustic distance from the end of the magnetostrictive stub to the feedthrough or weld long in comparison to the distance between the furthest separated sensors reflective so that any multiple reflections involving the feedthrough or weld will not overlap the primary sensor reflections. Any reflections from sheath-sensor contact, however, necessarily occur in the vicinity of the sensor elements. since this is where the sheath is located. Since the sheath is reguired in the present case to eliminate the possibility of even larger reflections from contact between the sensor and $\mathrm{UO}_{2}$, it is important to minimize the sheath-sensor contact.

In the present work, the following steps have been taken. A compromise has been rnade in sheath-sensor spacing to minimize contact area while not jeopardizing thermal energy transfer into the sensor fron the sheath. At present, the sheath ID is $0.7 \mathrm{~mm}$, matched to a $0.5 \mathrm{~mm}$ OD sensor. An attempt has been made to obtain very straight sensor wires and sheaths. The thoriated tungsten sensor wires (centerless ground) are quite straight, while the sheaths tend to be slightly warped. Tungsten-rhenium sheaths used in early trials were generally warped by less than $0.5 \mathrm{~mm}$ in a $100 \mathrm{~mm}$ length, while $\mathrm{ThO}_{2}$ sheaths tended to have greater 
warpage (to 1-2 $\mathrm{mm}$ in $150 \mathrm{~mm}$ length), which was generally concentrated near one end. Because some contact was unavoidable, means to isolate that contact or localize it were attempted. Loose wraps of a fine tungsten wire (25-75 $\mu \mathrm{m}$ diameter) provided satisfactory isolation of contact points at low temperatures but were subject to contact welding, resulting in more substantial reflections at temperatures above $2300^{\circ} \mathrm{C}$. Standoffs consisting of small nubs of tungsten, laser-welded to the sensor at intervals, have been used by others ${ }^{11}$ and were investigated in the present study. However, it was difficult to weld sufficiently small nubs to the sensors to prevent rather large reflections at those nubs. Although these could be placed midway between sensor reflections and possibly not interfere directly with measurements, the additional signals were confusing and judged not desirable. Further, the nubs can stick to tungsten sheaths at high temperatures, both modifying the shape of the reflection and increasing its amplitude. Thus, for several reasons, standoffs were also rejected in the present study. Alternatively, it was found that $\mathrm{ThO}_{2}$ sheaths did not develop sticking problems at high temperatures as had the tungsten sheaths. There was no reaction apparent between tungsten and $\mathrm{ThO}_{2}$ at temperatures as high as $2900^{\circ} \mathrm{C}$. Further, there was generally not seen in the furnace experiments any evidence of temperature measurement error due to the contact which invariably occurred due to the as-received warpage of the $\mathrm{ThO}_{2}$ sheaths mentioned earlier. The $\mathrm{ThO}_{2}$ sheaths had an adatelonal benelit in being low in thermal conductivity relative to tungsten, so that the Tho 
sheaths didinot contribute substantially to axial heat losses in the sensor: The principal arawbacks of the $\mathrm{ThO}_{2}$ sheaths relative to tungsten were an increased brittleness, potentially resulting in broken sheaths during an experiment, and a possibility of interference in high temperature'measurements of long duration due to vaporization of $\mathrm{ThO}_{2}$ and condensation on the sensor wire at another location where the temperature was lower.

\section{Rotating Sensor Concept}

Because some temperature measurement errors which occurred in the in-core reactor experiments (to be discussed in section 4) may have been related to sheath-sensor contact, possibly alternative techniques of preventing reflections between sheath and sensor have been sought. One which may have a great deal of promise has been suggested by Lynnworth. 15 He found that relative motion between sensor and sheath minimized reflections at contact points. Either axial or rotary motion was effective, with relative surface velocities of about $10 \mathrm{~min} / \mathrm{s}$ giving a marked decrease in spurious reflections. This technique has not been used at high temperatures previously, but may give relief from the contact welding problems encountered when using tungsten sheaths with tungsten sensors. Tungsten sheaths might be more desirable to use than $\mathrm{ThO}_{2}$ sheaths due to their superior ruggedness at high temperatures. However, with either $\mathrm{ThO}_{2}$ or tungsten sheaths, the noving sensor concept might provide more accurate data by suppressing spurious reflections due to casual contact between sensor and sheath. 
Thus far, it has been deterinined that the sensor gives undistorted signals while being rotated. Rotation is accomplished using a small dc motor, attached through a small diameter plastic coupler to the end of the remendur section. The plastic provides a sufficiently great impedance mismatch to remendur that no significant signal distortion occurs at the coupling. The sensor can be kept in alignment using small, loose-fitting bearings or stationary guides with slightly oversized clearance holes. It is planned to use a vacuum-tight cylindrical cover over the sensor coil and motor to alleviate the need for a rotating vacuum seal feedthrough, for both furnace and in-core experiments. Furnace experiments using rotating sensors with tungsten and thoria sheaths are planned for the near future.

\section{APPLICATIONS OF ULTRASONIC THERMOMETRY IN REACTOR EXPERIMENTS}

As mentioned earlier, the primary impetus for the development of ultrasonic thermometers was the measurement of very high temperatures in reactor safety experiments. In this section are described the first reactor safety experiments to which the ultrasonic thermometry technique has been applied.

The FAHR Molten Fül pool experimental program is concerned with thc interaction of very hot fuel with reactor structural or sacrificial materials. The approach is to use fission-heated fuel to obtain sustained, intrinsic heating which rather closely approximates the decay heated case. This experimental method also allows the fuel to interact with real structural and core 
retention materials at the actual temperatures of interest. The main goal of the in-core experiments is to measure fuel temperatures and internal heat flows in molten fuel, molten steel, and solid fuel crusts surrounding fuel pools.

A series of three in-core experiments has been conducted to date. The first two contained only $\mathrm{UO}_{2}$ particulate and the third had $\mathrm{UO}_{2}$ particulate overlying a 304 ss disc. Each of these experiments was contained inside two nested pressure vessels as shown in Figure 11. The assembled package was placed into the Annular Core Pulsed Reactor (ACPR) for the experiment.

In each of the two fuel-only in-core experiments, MP-1, and MP-2, $834 \mathrm{~g}$ of fully enriched $\mathrm{UO}_{2}$ was fission heated at an ACPR power level of $600 \mathrm{~kW}$. The $\mathrm{UO}_{2}$ specific power was about $2.4 \mathrm{~kW} / \mathrm{kg}$ resulting in a $2 \mathrm{~kW}$ experiment power level. The fuel was a particulate with a particle size distribution of 0.1 to $1.0 \mathrm{~mm}$ and a stoichiometry of $\mathrm{UO}_{1.99}$. The $\mathrm{UO}_{2}$ was contained in a 3-mm-thick $\mathrm{ThO}_{2}$ crucible which was $64 \mathrm{~mm}$ in outside diameter and in height as shown in Figure 12. Also shown in.Figure 12 is a schematic of a 5-element ultrasonic thermometer and $\mathrm{ThO}_{2}$ sheath. In each experiment, two of these sensors were placed near the axial centerline of the fueled region. The elements were 9-10 mm long. The end of the sensor was initially about $4 \mathrm{~mm}$ above the crucible bottom to allow for thermal expansion effects during the experiment. A $1: 5 \mathrm{~mm}$ length cylinder of tungsten or $\mathrm{ThO}_{2}$ was used to plug the end of the sheath below the sensor. The thoriated tungsten rod was $0.5 \mathrm{~mm}$ in oiameter while the $\mathrm{ThO}_{2}$ sheath was $0.7 \mathrm{~mm}$ ID $\times 1.4 \mathrm{~mm}$ OD. 
In MP-1, the duration of reactor heating was 17.7 minutes, during which the ultrasonic thermometry data indicated that the fuel reached incipient melting. For $M P-2$ the powered portion of the experiment was 19 minutes which resulted in an indicated melt of about 15 percent of the fuel according to post-experiment $x-r$ adiography.

During both experiments the tungsten-rhenium thermocouples in the very high temperature zones failed at relatively low temperatures $\left(1700-1800^{\circ} \mathrm{C}\right)$. In contrast, both ultrasonic thermometers provided temperature data to the highest temperatures $\left(2860^{\circ} \mathrm{C}\right)$. In $\mathrm{MP}-1$, one ultrasonic thermometer indicated that the $\mathrm{UO}_{2}$ particulate reached incipient melting just prior to the termination of fission heating. The thermometer record for this case is shown in Figure 13. Here $\mathrm{UO}_{2}$ melting is suggested by both the indicated maximum temperature on the center sensor element and by the sudden shifts in apparent temperature of several of the sensor elements. The shifts are believed to be indications of fuel motion at melting causing temporary perturbation of the ultrasonic signals rather than an actual temperature change.

In addition to temperature-time data, the ultrasonic thermometers showed a clear indication of a temperature gradient within the fuel, as predicted by heat transfer calculations. Figure 14 shows a temperature profile near incipient melt, taken from the data of Figure 13. Also included are calculated temperature data under similar conditions. 
The data acquired during the first two in-core experiments were much less satisfactory than from the laboratory experiments, due to the more complex physical arrangement of the in-core experiments. Figure 13 shows temperature measurement errors as high as $100^{\circ} \mathrm{C}$ (based on calculated temperature histories) during the reactor-powered portion of the run (0-18 minutes), while even larger errors are apparent following the reactor shutdown. The other sensor in MP-1 and both sensors in MP-2 gave less accurate data. For these first two in-core experiments, the sensors were contained within 150-mm-long $\mathrm{ThO}_{2}$ sheaths for protection from contact, with the $\mathrm{UO}_{2}$ bed. Because the sheaths were generally somewhat warped, there was some binding between the sensor line and the sheath. Further, there was an s-bend in each sensor to acconmodate a feedthrough in the lid of the inner steel containment vessel. The resulting alignment problems caused additional binding between sensor and sheath which may have been accentuated during the experiment by the uneven thermal expansion of various parts of the experiment capsule. Finally the large temperature gradients in the fuel bed during the in-core experiment may have caused non-uniform fuel motion which could have further warped or even broken the $\mathrm{ThO}_{2}$ sheaths during the later portions of the experiments.

An additional problem encountered was a possible interaction between the $\mathrm{ThO}_{2}$ sheath and the surrounding low density $\mathrm{ZrO}_{2}$ insulation (see Fig. 1l). During assembly the fragile $\mathrm{zrO}_{2}$ insulation pieces sometimes sloughed off a powdery residue. If some of this powder fell inside the $\mathrm{ThO}_{2}$ sheath, eutectic melting 
of the $\mathrm{ThO}_{2}$ and $\mathrm{ZrO}_{2}$ could occur above $2600^{\circ} \mathrm{C}$ causing interference with the ultrasonic thermometer readings. This problem was minimized in the third experiment by a more careful assembly procedure.

The third in-core experiment, MP-3S, involved fission heating $628 \mathrm{~g}$ of fully enriched $\mathrm{UO}_{2}$ at $1.9 \mathrm{~kW} / \mathrm{kg}(475 \mathrm{~kW}$ ACPR power) to melt an underlying $224 \mathrm{~g}$ sample of 304 stainless steel. The steel was in the form of a solid dișk, $12.7 \mathrm{~mm}$ thick, and $53.2 \mathrm{~mm}$ in diameter. The lower ultrasonic sensor element for each of the two sensors was almost entirely within the steel disk.

For this last experiment, modifications were made to the lid feedthrough so that straight sensors could be used. Somewhat larger reflection coefficient notches were also used (35\%, vs. $20 \%$ for MP-1 and MP-2), to minimize the effect of spurious reflections due to possible binding of sensor and sheath. Finally, care was taken to prevent any $\mathrm{ZrO}_{2}$ powder from entering the space between sensor and sheath.

Figure 15 shows the ultrasonic data from two of the sensor elements, compared with the response of the bed and steel calculated using a two-dimensional heat transfer code. As seen, with the exception of some spurious data early in the experiment on one sensor element, the agreement between calculations and measurements of steel temperature and maximum fuel temperature is reasonably good. A temperature arrest in the steel near $1400^{\circ} \mathrm{C}$ corresponding to the steel melting transition is clearly seen. The lower measured rate of $\mathrm{r}$ ise in the fuel temperature above $2100^{\circ} \mathrm{C}$ is believed to be real, and apparently indicates 
an inadequate expression for thermal conductivity used in the calculations.

Figure 16 shows the power of the ultrasonic technique for measuring temperature profiles. Here, the temperature profiles in the fuel-steel bed measured by each ultrasonic thermometer are compared to calculated values at several points in time during the experiment. The agreement is in general very good except for high steel temperatures measured by one sensor, and a discrepancy between measured and calculated fuel temperatures at later times, as discussed above. 
5. CONCLUSIONS

As demonstrated by the data shown, the ultrasonic thermometry technique has been very useful for determining the temperatures and temperature profiles within the Molten Pool in-core experiments. No other known technique could be used, since thermocouples were unsuccessful above $2000^{\circ} \mathrm{C}$. Optical pyrometry was not applicable due to the limited physical access of the experiments, as well as the opaque nature of the sample whose internal temperature was to be measured. Nevertheless, the considerable uncertainty and obvious inaccuracy observed in the early experiments demonstrates a need for additional work to obtain a reliable, accurate temperature monitor. It is believed that a combination of attention to unwanted reflections, especially at the pressure feedthrough and between sensor and sheath, will be especially important. The pressure feedthrough reflection can be eliminated by including the entire sensor assembly within the pressure vessel, or it can be moved sufficiently far from the end reflection to prevent overlap of the primary signal reflections. Sensor-sheath reflections can be minimized by utilizing a rotating sensor, as previously described. Future Molten Pool in-core experiments will utilize sensors modified in these ways.

The ultrasonic thermometry technique could be used in a variety of reactor safety experiments, especially those involving extremely high temperatures or requiring temperature gradient measurements. Studies have begun of sensors for measuring temperature profiles in the Debris Bed experiments. 5,10 
Appendix A -- Signal Processing Electronics

As previously indicated, multiple sensor/multiple element ultrasonic thermometers were to be used to support the LMFBR experimental program. As a result of this requirement, the programmable signal processing system shown in Fig. Al was developed. Basically, this system can arive either one or two sensors, where either sensor can have from 1 to 5 sensing elements. Specific reflections from the elements are manually selected and the electronics generates a start/stop signal for each element. These start/stop signals are then multiplexed to a single time interval counter so that the counter provides a serial readout of the time intervals for all the elements, where the number of elements can be from 1 to 10 . By using a counter having digital output, the data can be used to drive a data logger or as direct input to a computer, as was done for these experiments.

The most unique feature of this system is the manual signal selection process. The desired signal is selected by aligning a narrow ( 0.5 to $1.0 \mu \mathrm{s})$ gate pulse with the desired zero crossing of the selected signal. Once this alignment is accomplished, a signal tracking servo is engaged, causing the gate pulse to automatically track the selected zero crossing. The required start/stop signal is then generated by "ANDing" the video (ultrasonic) and gate signals. In previous systems, the gate was manually controlled at all times, or it had a very limited range, thus making the multi-element sensor rather impractical.

The major elements of Fig. Al are discussed in detail in the following sections of this Appendix. 
Sensor Driver and Preamp

Although several commercial oulse generators were investigated to drive the sensor coil, a simple delay line/mercury-wetted relay pulser produced the best results. In the final design, $20 \mathrm{~m}$ of RG58 cable charged to 300 volts was switched into the sensor coil, as shown in Fig. A2. The pulser and coil were normally connected by 10 m of coaxial cable, to allow use of the pulser at reactor poolside, while the coil was in the reactor core. For a typical sensor, this system provides a current pulse of 0.5 amperes, with a pulse width of $0.5 \mathrm{\mu s}$ and a repetition frequency of $60 \mathrm{~Hz}$.

The sensor coil is used for both excitation and interrogation of the acoustic signal. The input to the preamp is protected from the large $(\sim 150 \mathrm{~V})$ excitation pulse by a hard limiter. This limiter does not affect the return signals as they are well below the diode threshold of $0.5 \mathrm{~V}$. The preamp itself is normally set for near unity gain and it simply acts as a line driver to transmit undistorted signals through a $20 \mathrm{~m}$ coaxial cable to the signal conditioning electronics in the control room.

A sync signal for use in the gate servos is generated in a circuit parallel to the sensor coil by diode limiting the excitation pulse. The parallel combination of the sensor coil and the sync signal electronics, each nominally $100 \Omega$, provides a system well matched to the $50 \Omega$ coaxial cable impedance.

\section{Video Amplifier and Limiter}

A video amplifier is required to bring the relatively small (typically 5 to $100 \mathrm{mV}$ ) video signals up to a useable level. In the present system, the video signal is amplified, hard limited 
and appliea to a low-level sense amplifier. The resultant output is a TTL-compatible series of logic transitions; where the transitions correspond to the zero crossings of the input video signal. As shown in Fig. A3, the video amplifier consists of two differential gain stages followed by an integrated circuit sense amplifier. The sense amplifier output is fanned out to drive six AND gates and six NAND gates which. in turn feed six gate control servos. The parallel. AND/NAND outputs are provided so that the gate control servos can be locked to either a positive- or nega- : tive-going zero crossing. A low-level video output is also pro-. vided, for viewing on an oscilloscope. This signal is used in setting up the servo systems.

The input differential amplifiers provide a number of desirable characteristics. For example, they provide a band-pass function with cutoff frequencies of approximately 0.2 to $2.2 \mathrm{MHz}$. This bandpass characteristic reduces system noise while maintaining the required gain at the signal frequency of approximately $1 \mathrm{MHz}$. In: addition, the reduced.low frequency response improves the overload recovery of the amplifier, a necessary characteristic since the amplifier sees both the transmitted and received pulses.

The differential amplifier also provides hard limiting of an input signal without being driven. into saturation, "with the attendant charge storage and (variable) overload recovery times which occur in other types of amplifiers. The hard limiting is provided through three stages of diode limiting using FD700 diodes. The maximum reverse recovery time for the FD700 is approximately. 0.7 ns and thus it does not degrade amplifier performance. 
For a simple amplifier of the type shown in Fig. A3, the stage's differential voltage gain, $A_{y^{\prime}}$ is given by

$$
A_{V}=\frac{R_{C}}{R_{E}+\frac{k T}{q I_{E}}+\frac{R_{c}}{\beta}}
$$

with

$$
\begin{aligned}
A_{V} & =\text { voltage gain } \\
R_{C} & =\text { collector loäd resistance } \\
R_{E} & =\text { emitter resistance } \\
k & =\text { Boltzmann constant } \\
T & =\text { absolute temperature } \\
q & =\text { electron charge } \\
I_{E} & =\text { emitter current } \\
B & =\text { common-emitter current gain }
\end{aligned}
$$

Unfortunately, if the device is used as a single-ended amplifier, only half this gain is actually realized. This shortcoming can be overcome by using a current mirror type load, as provided by the 2N5119 of this design. The current mirror also improves the amplifier's high frequency response by (I) greatly reducing the input Miller capacitance and (2) allowing the use of a very low collector load resistance.

A high speed sense amplifier (UA710) is used to provide final signal processing in the video amplifier. With the overdrive provided by the input differential amplifiers, this device provides a propagation delay and $r$ ise time of under $40 \mathrm{~ns}$ for both positiveand negative-going transitions. Since these delays are constant, they do not affect system accuracy. 
Finally, a second sense amplifier (U7) was included on this board to process the sync signal so that it is TTL-compatible. This amplifier also provides a variable offset so that it can be adjusted to reject the reflected acoustic and other noise pulses.

\section{Gate Control Servo and Zero Crossing Detector}

As previously indicated, the gate control servo produces a narrow $(\sim 0.5$ to $1.0 \mu \mathrm{s})$ gate pulse which can be locked to a selected video zero crossing. Time coincidence of these two pulses can then be used as a start or stop signal to an electronic timer. Six gate control servos are reguired for each 5-element sensor.

The basic operating principle of this system is illustrated in the block diagram of Fig. A4. Initially, the servo loop gain and the voltage on the base of $\mathrm{Ql}$ are both zero. Thus, the collector current of Al can be controlled by the gate position pot, RI. This collector current then controls the pulse width of SSI, over a range of approximately 50 to 1500 us.

Operation of the gate servo system is initiated by the sync (transmit) pulse. This pulse starts the timing interval for ssi and it resets the stop/start flip-flop (FFI).

when ssl times out, the trailing edge of its output pulse triggers SS2, which produces a fixed duration ( 10 Hs) output pulse. This SS2 pulse provides two functions. First, it resets the integrator (A1) through the FET switch $\mathrm{Q} 2 \mathrm{~A}$ and, secondly, the leading edge of its output pulse triggers SS3. Thus, SS2 and SS3 are on simultaneously but SS2 will always be turned on before ss3, since the leading edge of SS2 triggers SS3 (if SS2 is triggered 
on first, a double gate pulse will be produced, causing very erratic behavior).

The output pulse duration from SS3 can be varied from approximately 10 to 12.5 is. This output performs two functions. First, it turns on $Q 2 B$, connecting a summing junction $\left(R_{5}\right.$ and $\left.R_{6}\right)$ to the integrator input (note that the integrator will not start integrating until ss 2 times out, since it is held in the reset mode by $Q 2 A)$. The second output from $S S 3$ is combined with the sS 2 output, through clamp transistor A3. After ss2 times out, this produces a gate pulse whose width can be varied from approximately 0 to $2.5 \mathrm{\mu s}$, via the gate width control (R4) on SS3. This gate pulse and the (square wave) video signal then drive an AND gate, the output of which represents the selected video signal zero crossing.

The zero crossing signal is used to set the zero crossing flip-flop (FFl); which was initially reset by the sync pulse. The FFl output provides the required timer start/stop signal and it also provides the second input to the integrator summing junction, by turning on Q4. Reference should now be made to the timing diagram of Fig. A5:

As. shown in Fig. A4, the syric pulse triggers SSl on at zero time. When Ssl times out, SS2 and ss3 are triggered on. The integrator is held in the rect mode as long as s.s? is on. When ss2 times out $\left(t_{1}\right)$, the integrator begins integrating the current which is being injected by R6 and its output voltage begins swinging negative at the rate of

$$
\frac{d v}{d t}=\frac{v_{1}}{R_{6} C}
$$


The output will continue ramping negative at this rate until time $t_{2}$, when the AND gate output goes high, due to the coincidence of the gate and the signal zero crossing. At $t_{2}, Q 4$ is turned on and $R_{5}$ begins conducting a current of $v_{2} / R_{5}$ from the integrator summing junction. If $\left|v_{1}\right|=\left|v_{2}\right|$ and $R_{5}=R_{6} / 2$, the integrator output will begin ramping positive at $t_{2}$, again at the rate of

$$
\frac{d V}{d t}=\frac{v_{1}}{\mathrm{P}_{6} \mathrm{C}}
$$

At $\mathrm{T}_{3}$ ss3 turns off, terminating the gate pulse and disconnecting. the summing junction from the integrator. The inţegrator then holds its last output voltage value until the next timing cycle. Assuming that the positive and negative ramp rates are equal, the integrator output wil be zero at $t_{3}$ if $t_{2}-t_{1}=t_{3}-t_{2}$ : that is, if the signal zero crossing occurs in the midale of the gate pulse. If $t_{2}-t_{1}>t_{3}-t_{2}$, the output will be negative and if $t_{2}-t_{1}<t_{3}-t_{2}$, the output will, positive. This timeproportional bipolar error signal from the integrator is the driving function which controls the servo loop.

The integrator output ärives a low-phase filter ( 0.06 Hz) and amplifier. Although the amplifier gain is only 6 , the overall loop gain is adequate to provide the reguired servo action. Assuming that the integrator output is zero (the signal zero crossing is centered, in the gate pulse), the loop gain can be increased without affecting the base voltage of 21 . Once the loop is closed, any motion of the signal relative to the gate pulse will change the base voltage and collector current of Ql. This current change 
varies the pulse width from SSl, thus causing the gate signal to shift in time, which re-centers the zero crossing signal.

Over a period of time, large signal movements $(10 \mathrm{\mu s}$ or greater) may occur. These will require large error signals to shift the gate pulse and, consequently; the zero crossing signal will become somewhat offset from the center of the gate pulse. However, as long as it remains within the gate pulse, time coincidence of these two signals still provides an accurate start/stop timing signal.

As "previously indicated, the open loop gain of this system is relatively high and unfortunately, it is a function of gate position, i.e., the value of Rl. For example, loop gain varies by a factor of 30 between minimum and maximum gate delay. Loop stability is attained by the low pass filter and the manually adjustable loop gain control. For relatively short delays (in the range of 100 to $300 \mu \mathrm{s})$, the loop is stable with maximum loop gain. However, for long delays (l ms or greater) the maximum loop gain is sufficient to produce minor instability. This instability is manifest as a time jitter of the gate pulse and not the large amplitude oscillations normally associated with servo systems. This instability can be eliminated simply by reducing loop gain using the loop gain pot.

To set up the servo, the loop gain is set to zero, the gate pulse is aligned with the desired zero crossing, the zero crossing polarity is selected and the loop gain is increased until the gate signal begins to jitter. Loop gain is then reduced slightly to eliminate the jitter. The channel is now locked in. 
By connecting a zero-center meter to the integrator output, one can observe gate cètering during an experiment and, if required, the gate position pot can be readjusted without opening the servo 100p and losing data. This adjustment is not generally required, as the servos track very well for relatively large (many $\mu s$ ) signal excursions, but the meters do provide a quick visual check of servo performance.

A schematic of the gate control servo is shown in Fig. A6. The major shortcoming in this system is the CD4016 FET switch. A $0.5 \mu \mathrm{s}$ gate pulse severely taxes this device's switching speed and if narrower pulses are needed, faster FET switches would be required. However, the CD4016 is quite adequate for any gate pulse longer than $0.5 \mu \mathrm{s}$.

\section{Multiplexer}

The present multiplex system was designed such that one timer can be used to read sequentially the outputs from either one or two sensors, where either sensor may have from one to five active elements. The system will automatically sequence through all elements or it can be manually stepped through the sequence at any desired rate. The required system inputs are:

1) Selection of either one or two sensors;

2) Selection of the number of elements per sensor,

3) Selection of auto or manual sequencing,

4) Stop/start, signals from all sensors and,

5) A "done". signal from the timer. 
The system outputs are:

1) One "start" and one "stop" signal line to control the timer,

2) A top-of-page sync pulse, to indicate when element \#l of sensor \#l is being read and,

3) A train of data sync pulses, one pulse per sensor element.

Assuming the timer has a digital output, the data can be printed out directly or it can be fed to a computer for real time data reduction.

A schematic of the multiplex circuit board is shown in Fig. A7. The basic circuit functions for a single sensor are as follows. The "done" signal from the timer increments a 7419 decade counter. The decade counter drives a 7485 digital comparator and two 74l5lA 8-line to l-line decoders. The second set of comparator inputs are derived from the element selector switch and when the decade counter and element switch inputs match, the comparator resets the decade counter and the sequence starts over again. The decoders (74151A's) pass the selected stop/start signals to a single start and single stop terminal, depending upon the state of the decade counter, e.g., for element 1 , servo 1 provides the start and servo 2 the stop; for element 2, servo 2 provides the start and servo 3 the stop, etc.

These basic functions are essentially duplicated when a two sensor system is used. The major difference is that the reset pulse from the 7485 comparator now sets a flip-flop which enables a second counter, comparator, decoder system. 'The comparator for this serond sensor then proviłes the system reset function. 
Addition of a second sensor also requires the use of a 74157 2-line to l-line decoder to provide additional fan-in of the stop/start signals.

If one of the servo loops should drop out of lock, the timer may not generate a "done" signal for this element and the multiplexer would stop on the affected element. To prevent data loss from the unaffected elements, a demand timer has been included in the multiplex system (the $\mathrm{U} 2, \mathrm{U} 3$ and $\mathrm{U} 28$ one-shots). If this circuit does not receive the "done" signal before the pre-programmed demand time interval, it automatically increments the multiplexer to the next sensor element. Assuming the out-of-lock servo is driven by an interior sensor element, the next element will also be affected (i.e., if the first element has no stop signal, the second element will have no start signal) and the demand timer will again increment the multiplexer.

Propagation delay effects in the multiplexer were minimized by:

1) using high speed TTL logic (series 74),

2) minimizing the number of gates and

3) ensuring that all start and stop signals encounter the same number and type of gates.

Obviously, these steps will not totally eliminate propagation delay but they do cancel the effect of the inherent gate delay and only the unit-to-unit delays will affect the data. The effects of these unit-to-unit variations are minimized by laboratory calibration of the sensors. 
Appendix B -- Evaluating the Effect of Overlapping Signals on the Accuracy of Ultrasonic Thermometry Data

Arave and Buchenauer ${ }^{11}$ recently evaluated the phase shift of ultrasonic thermometry signals resulting from interference from an overlapping standoff echo. In this Appendix, we will use the same approach to a more general discussion of the effects of overlapping reflections. For this discussion, we will focus on secondary reflections; however, the results could be applied to any reflections overlapping the primary reflections.

For purposes of discussion, consider Figure Bl, which shows a five-element ultrasonic thermometer, along with the six primary reflections which are the start and stop signals for those five elements. Besides these primary reflections, there will be overlapping secondary and higher-order reflections which will be more or less important, depending on their amplitude and phase relationship to the primary signals. For example, if the elements are equaliy spaced, and the temperature uniform, we would expect that the primary signal from reflection $3\left(k_{3}\right.$, in Fig. Bl.c) would be generated in the pulse coil at the same time as (i.e., be overlapped by) a secondary signal resulting from successive reflections at notch 2 , notch 1 , and notch 2 , designated as $R_{21} 2$ in Fig. Bl.d. Likewise, primary reflection $\mathrm{R}_{4}$ is overlapped by three secondary reflections, $R_{5}$ by six secondary reflections, and $R_{6}$ by ten secondary reflections as tabulated in Table BII. Inspection shows that $R_{2}$ and $R_{1}$ are not overlapped by any secondaryj reflections. 
If the secondary signals are in phase with the primary signals, then only the magnitude of the signals will be affected, and' no measurement errors in delay time will result. However, in an actual measurement situation, the temperature gradient along the sensor wire, and differences in sensor length, will result in overlapping but out-of-phase secondary reflections. These will change the apparent phase of the primary signal and introduce temperature measurement errors.

In order to treat the overlap effects mathematically, we will make the simplifying assumption that the signals are sinusoidal, rather than damped waves. Since we are principally interested in the larger amplitude portions of the signals, this assumption will not cause significant error.

$$
\begin{aligned}
& R_{p}=A \sin \omega t \\
& R_{s 1}=B_{1} \sin \left(\omega t+\delta_{1}\right) \\
& R_{s 2}=B_{2} \sin \left(\omega t+\delta_{n}\right) \\
& \dot{\cdot} \\
& \dot{R}_{s n}=B_{n} \sin \left(\omega t+\delta_{n}\right)
\end{aligned}
$$

Here $R_{p}$ is the time-resolved primary reflection amplitude, and $R_{s}{ }^{\prime}$ $R_{s 2}, \ldots . R_{s n}$ are the reflection amplitudes of the first to $n^{\text {th }}$ secondary reflections, which are out of phase with the primary reflections by $\delta_{1}, \delta_{2} \ldots \delta_{n}$. The maximum signal amplitudes are $A,{ }^{B}{ }_{1}, B_{2}, \ldots . B_{n}$. The resultant signal from the summation of overlapping primary and secondary reflections is 
1) $R=A \sin t+B_{1} \sin \left(\omega t+\delta_{1}\right)+B_{2} \sin \left(\omega t+\delta_{2}\right)$

$+\ldots+B_{n} \sin \left(\omega t+\delta_{n}\right)$

$=A \sin \omega t+B_{1}\left(\sin \omega t \cos \delta_{1}+\cos \omega t \sin \delta_{1}\right)+\ldots$

$+B_{n}\left(\sin \omega t \cos \delta_{n}+\cos \omega t \sin \delta_{n}\right)$

$=\left(A+B_{1} \cos \delta_{1}+\ldots+B_{n} \cos \delta_{n}\right) \sin \omega t+\left(B_{1} \sin \delta_{1}+\ldots\right.$

$\left.+B_{n} \sin \delta_{n}\right) \cdot \cos \cot \omega$

This can also be expressed as a single resultant sinusoidal wave which is phase-shifted from the primary reflection by $\gamma$.

2) $\quad \dot{R}=C \sin (\omega t+\gamma)=C \sin \omega t \cos \gamma+C \cos \omega t \sin \gamma$

Combining 1 and 2 ,

3) $\mathrm{C} \cos Y=A+B_{1} \cos \delta_{1}+\ldots+B_{n} \cos \delta_{n}$

4) $C \sin \gamma=B_{1} \sin \delta_{1}+\ldots+B_{n} \sin \delta_{n}$

which together give

5)

$$
\frac{\cos \gamma}{\sin \gamma}=\cot \gamma=\frac{A+B_{1} \cos \delta_{1}+\ldots+B_{n} \cos \delta_{n}}{B_{1} \sin \delta_{1}+\ldots+B_{n} \sin \delta_{n}}
$$

Before using this general expression to look at potential temperature errors, let us reproduce some of Arave and Buchenauer's treatment of the effect of a single secondary reflection. Using

6)

$$
\cot \gamma=\frac{A+B \cos \delta}{B \sin \delta}=\frac{A}{B} \csc \delta+\cot \delta
$$


let us find the phase shift $\delta$ which produces the maximum change in $\gamma$, and hence, the maximum error in. indicated temperature. For this, we need to find $\frac{d \gamma}{d \delta}=0$.

7) $\frac{\mathrm{d} \cot \gamma}{\mathrm{a} \delta}=-\csc ^{2} \gamma \frac{\mathrm{d} \gamma}{\mathrm{d} \delta}=\frac{\mathrm{A}}{\mathrm{B}}(-\csc \delta \cot \delta)-\csc ^{2} \delta$

8) $\frac{\mathrm{d} \gamma}{\mathrm{d} \delta}=\frac{\mathrm{A}}{\mathrm{B}} \frac{\csc \delta \cot \delta}{\csc ^{2} \gamma}+\frac{\csc ^{2} \delta}{\csc ^{2} \gamma}$

$$
\frac{d \gamma}{d \delta}=\left(\frac{A}{B} \cos \delta+1\right) \frac{\sin ^{2} \gamma}{\sin ^{2} \delta}
$$

Setting $\frac{d \gamma}{d \delta}=0$

9) $\cos \delta=-\frac{B}{A}$

9a) $\delta\left(\gamma_{\max }\right)=\cos ^{-1}\left(-\frac{B}{A}\right)$

Equation 6 may be rewritten using trigonometric identities

10) $\cot \gamma=\frac{A / B+\cos \delta}{\sqrt{1-\cos ^{2} \delta}}$

and substituting from Eq. 9 to find the maximum value of $r$,

11) $\cot \gamma=\sqrt{(A / B)^{2}-1}$

which is equivalent to

12) $\gamma_{\max }=\sin \frac{B}{\bar{A}}$ 
For values of $\frac{B}{A}$ which are small, $\delta\left(\gamma_{\max }\right)$ will be near $90^{\circ}$, and $\gamma_{\max }$ will be near $0^{\circ}$.

Let us use these results to evaluate potential ercors with ultrasonic thermometers similar to those described in this report. A maximum acceptable temperature error might be $15^{\circ} \mathrm{C}$, or about the calibration uncertainty. If we assume a $10 \mathrm{~mm}$ length sensor of thoriated tungsten, a $15^{\circ} \mathrm{C}$ temperature change at $2500^{\circ} \mathrm{C}$ represents a time error of about $10 \mathrm{~ns}$ (see Figure 6). For signals whose center frequency is about $500 \mathrm{kHz}, 10 \mathrm{~ns}$ represents a $1.8^{\circ}$ phase shift $\gamma$. From Eq. $12,1.8^{\circ}$ is the maximum phase shift possible if the signal ratio $B_{1} / A$ is 0.031 . This phase shift in $\gamma$ will occur if $\delta$ is $100^{\circ}$. Thus, a secondary reflection with about $3 \%$ of the primary signal amplitude, and out of phase by $100^{\circ}$, will cause a $15^{\circ} \mathrm{C}$ temperature error at $2500^{\circ} \mathrm{C}$. Note that since the secondary reflections which we are considering always involve two reflections more than the primary reflection (see Fig. Bl), then a ratio of $B_{1} / A$ of 0.031 implies a reflection coefficient of $\sqrt{0.031}$, or 0.18 . 'That is, if the primary reflection coefficients are all 0.18 , then the secondary reflection coefticients will be $(0.18)^{3}$, and $B_{1} / A=0.031$. For comparison, reflection coefficients used in the present study were generally near 0.2 .

Tt. should also be noted that the above calculations assume only one secondary reflection overlapping only one reflected primary signal, where in fact the delay time is measured between two primary reflections and several secondary reflections can be present. Thus, in practice, larger errors could result if the effects of the secondary signals were additive. However, now 
let us refer to the more general case depicted schematically in Fig. Bl. As shown, no overlapping secondary reflections are possible with $R_{1}$ and $R_{2}$, while $R_{3}$, has one overlapping secondary reflection and multiple secondary reflections could affect $R_{4}$ ' $R_{5}$ and $R_{6}$. Let us for illustrative purposes calculate the temperature errors which resulted from the measured temperature profile in Figure 1.4. In Table BI we give the temperatures, delay times in microseconds and delay times expressed in terms of the number of cycles of a $500 \mathrm{kHz}$ signal (the approximate signal frequency).

For the calculations, the reflection coefficients are assumed to be 0.2 except for the end reflection coefficient of 1.0. The decrease in amplitude of the incident signal due to losses at earlier reflection points is small and ignored in this calculation. For each reflection $R_{1}, \ldots, R_{6}$, we calculate the phase angle $\delta$ for each secondary reflection which can overlap the particular primary reflection. Then, using Equation 5, we determine $\gamma$, the change of phase of the resultant signal.

As an example, for $\mathrm{R}_{4}$, there are three overlapping secondary reflections, $R_{323}, R_{312}$ and $R_{213} \cdots$. The last two are equivalent. Using the data from Table BI, the phase angles $\delta_{i}$ are

$$
\begin{gathered}
\delta\left(R_{4}-R_{323}\right)=360[8.311-(5.509+2.763)]=14.0^{\circ} \\
\delta\left(R_{4}-R_{213}\right)=\delta\left(R_{4}-R_{312}\right)=360[8.311-(5.509+2.747)]=19.8^{\circ}
\end{gathered}
$$

Erom the phase angles $\delta_{i}$, the phase angle of $Y\left(R_{4}\right)$ is calculated 


$$
\begin{aligned}
Y\left(R_{4}\right) & =\cot ^{-1}\left[\frac{A+B_{1} \sin 14^{\circ}+B_{2} \sin 20^{\circ}+B_{3} \sin 20^{\circ}}{B_{1} \cos 14^{\circ}+B_{2} \cos 20^{\circ}+B_{3} \cos 20^{\circ}}\right] \\
& =\cot ^{-1}\left[\frac{1+(.04)(.97+(2)(.94))}{(.04)(.243+(2)(.339))}\right] \\
Y\left(R_{4}\right) & =-1.9^{\circ}
\end{aligned}
$$

Thus, the effert of the three overlapping secondary reflections on $R_{4}$ is to shift the signal forward in time by $1.9^{\circ}$, or $10 \mathrm{ns:}$

Table II lists the calculated values of $\delta$ for each secondary reflection and of the resultant $\gamma$ for each primary reflection. Finally, for each sensor element $E_{i j}$, we determine $\gamma_{j}-\gamma_{i}$, and from this $\Delta t$. Using $\Delta t$ and Figure 6 calibration data, we finally obtain $\Delta \mathrm{T}$. These data are tabulated in Table III, and indicate temperature errors of -1.6 to $-14^{\circ} \mathrm{C}$ due to overlapping secondary reflections.

Although each set of temperature data will have its own unique combination of overlapping secondary reflections which will give a unique temperature error, these calculations suggest the possibility of minimizing the temperature errors by appropriate choice of sensor lengths. In the present case, the end element $\left(E_{56}\right)$ was about 158 longer than the other elements. As a result, all of the secondary reflections overlapping $R_{6}$ had a relatively large and constant phase angle $\delta$ with the end reflection $R_{6}$. This would have caused a rather large phase angle $\gamma\left(K_{6}\right)$ except that the amplitude of $R_{6}$ was five times laiger than any of the other primary reflections, so that the relative importance of 
each secondary reflection was less. In fact, the phase angle $\gamma\left(R_{6}\right)$ ended up fortuitously close to $\left(R_{5}\right)$, resulting in a relatively small error for $\mathrm{E}_{56}$. Although this combination occurred accidentally, it suggests the possibility of tailoring the sensor lengths to offset errors caused by temperature gradients, if these temperature gradients can be determined approximately in advance. The approach would be to determine the ratio of delay times per unit length between successive elements in the predicted temperature gradient, and then $f i x$ the element lengths in the inverse ratio to give nominally constant $\Delta t$ 's between all sensor elements. This would then give in-phase or nearly in-phase secondary reflections. Alternatively, or in addition, it should be possible to make corrections to the measured temperatures by calculations such as those described in this Appendix. 
Table BI

Raw Ultrasonic Thermometry Data" Converted to Cycles

$$
\text { of } 500 \mathrm{kHz} \text { Signal }
$$

$\begin{array}{ccccc}\begin{array}{c}\text { Sensor } \\ \text { Element }\end{array} & \text { T }\left({ }^{\circ} \mathrm{C}\right) & \begin{array}{c}\text { Delay Time } \\ (\mu \mathrm{s})\end{array} & \begin{array}{c}\text { Delay Time } \\ \text { in Cycles } \\ (500 \mathrm{kHz})\end{array} & \sum_{\text {Cycles }} \\ \mathrm{E}_{12} & 2515 & 5.493 & 2.747 & 2.747 \\ \mathrm{E}_{23} & 2693 & 5.526 & 2.763 & 5.509 \\ \mathrm{E}_{34} & 2770 & 5.603 & 2.801 & 8.311 \\ \mathrm{E}_{45} & 2715 & 5.580 & 2.790 & 11.101 \\ \mathrm{E}_{56} & 2561 & 6.305^{*} & 3.153 & 14.254\end{array}$

*This time longer because the end sensor element was about 158 longer. 
Table BII

Phase Shifts $Y\left(R_{i}\right)$ Calculated for Each Primary Reflection due to secondary Refiection Overlap

Primary Reflection
Over lapping

Secondary

Reflection
Phase Shift $\delta_{i}$ of secondary Reflection (degrees)
Resultant Phase Shift $\gamma\left(R_{i}\right)$ of Primary Reflection $\mathrm{R}_{\mathrm{i}}$ (degrees)

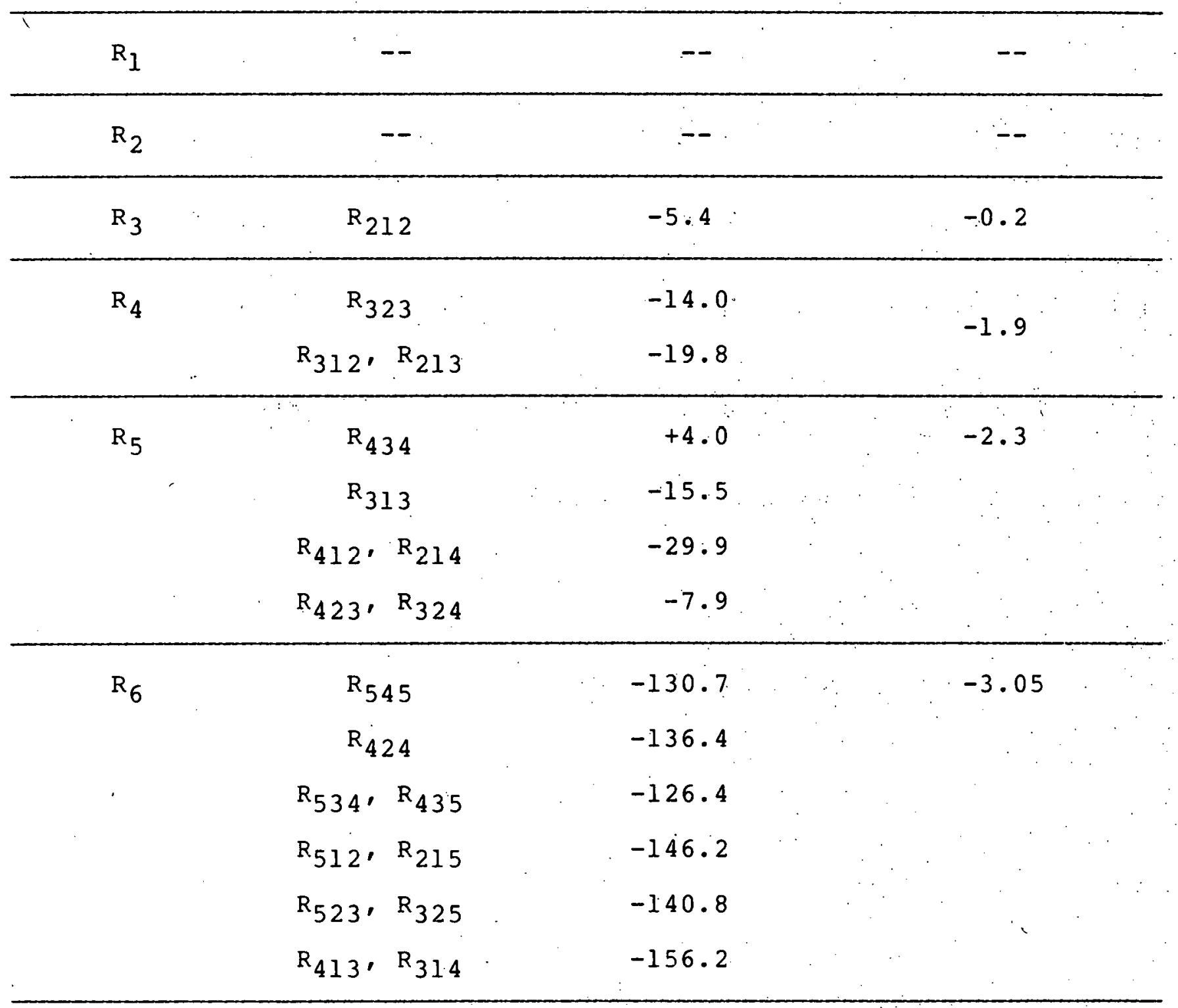


Table BIII

Temperature Errors Resulting from Secondary

Reflection Overlap of Primary Reflections

Sensor Element

$\left(E_{i j}\right)$.

$\mathrm{E}_{12}$

$E_{23}$

$\mathrm{E}_{34}$

$\mathrm{E}_{45}$

$E_{56}$

$$
\begin{gathered}
\Delta \gamma \\
\left(\gamma_{j}-\gamma_{i}\right) \\
(\text { degrees) }
\end{gathered}
$$

0

$-0.2$

$-1.7$

$-0.6$

$-0.75$
$-9.4$

$-14$

$-3.3$

$-5$

$\Delta t$

$(\mu s)$

$-1.1$

$-1.6$

$-4.2$

$\left({ }^{\circ} \mathrm{C}\right)$

0
$\Delta \mathrm{T}$ 


\section{References}

1. R. L. Shepard, R. F. Hyland, J. M. Googe, and J. R. McDearman, "Equivalent Circuit Modeling of Insulator Shunting Errors in High Temperature Sheathed Thermocouples," from Temperature: Its Measurement and Control in Science and Industry, Vol. 4, edited by H. H. Plumb, Instr. Soc. of America, p. 1841 (1972).

2. L. C. Lynnworth, E. P. Papadakis, D. R. Patch, K. A. Fowler, and R. L. Shepard, "Nuclear Reactor Applications of New Ultrasonic Transducer," IEEE Trans. Nucl. Sci., NS-18(1), p. 1 (1971).

3. A. E. Arave, F. E. Panisko, and J. A. Christensen, "High Temperature Ultrasonic Thermometry In-Reactor Fuel Rod Centerline Temperature Test Results," Aeroject Nuclear Co., Report No. ANCR-1091 (1972).

4. H. A. Tasman, H. E. Schmidt, J. Richter, M. Campana, and G. Fayl, "The TRESON Experiments - Measurement of Temperature Profiles in Nuclear Euels by Means of Ultrasonic Thermometers," European Institute for Transuranium Elements, Tech. Note No. k0277012 (1977).

5. J. B. Rivard, "Debris Bed Studies and Experiments at Sandia Laboratories," Sandia Laboratories Report No. SAND78-0299 (1978).

6. D. A. Powers, "Sustained Molten Steel/Concrete Interactions Tests--A Preliminary Report on the Feasibility of Experimental Techniques," Sandia Laboratories Report No. SAND77-1423 (1978).

7. L. C. Lynnworth and D. R. Patch, Matl. Res. Stanà. 10 (8), pp. 6-11, p. 40 (August 1970).

8. A. P. C. Thiele, Proc. Inst. Elec. Eng. 109B (Suppl. 22) p. 379 (1962).

9. A. Rothbart and L. Rosenberg, "A Theory of Pulse Transmission along a Magnetostrictive Delay Line," IEEE Trans. Sonics and Ultrasonics, Vol. PGUE-SU17, p. 32 (1957).

10. G. A. Carlson and H. G. Plein, "Refractory Metals for Ultrasonic Thermometry Application," Sandia Laboratories Report No. SAND79-1382 (1978).

11. A. E. Arave and J. Buchenauer, "Use of Tungsten--28 Thoria Ultrasonic Transmission Line and Sensor to Improve the Performance of High-Temperature Ultrasonic Thermometry," USNRC Report No. TREE-NUREG-1021 (1976).

12. L. C. Lynnworth, "Magnetostrictive Ultrasonic Probes," Parametrics Technical Memorandum UR-141 (1975). 


\section{References--cont'd}

13. A. W. Reed and D. W. Larson, Sandia Laboratories, private communications: October 6, 1976; November 5, 1976; Apri1 25, 1977; May 11, 1977.

14. H. C. Plein, G. A. Carlson. W. H. Sullivan, M. R. Goebel, A. R. Phillips, "Molten Fuel Pool Studies," in "Advanced Reactor. Safety Research Program Quarterly Report April-June 1.977 ," Sandia Laboratories Report No. SAND77-1134, p. 129 (1977); H. G. Plein and G. A. Carlson, "Molten Fuel Pool Studies," in "Advanced Reactor Safety Research Program Quarterly Report july-September 1977," Sandia Laboratories Report No. SAND77-1975, p. 99 (1978).

15. L. C. Lynnworth, private communication, 1977; L. C. Lynnworth Wear 4l, 1195 (1977); L. C. Lynnworth and J. E. Bradshaw, Matl. Res. Stand. 11 (3), 33 (1971). 

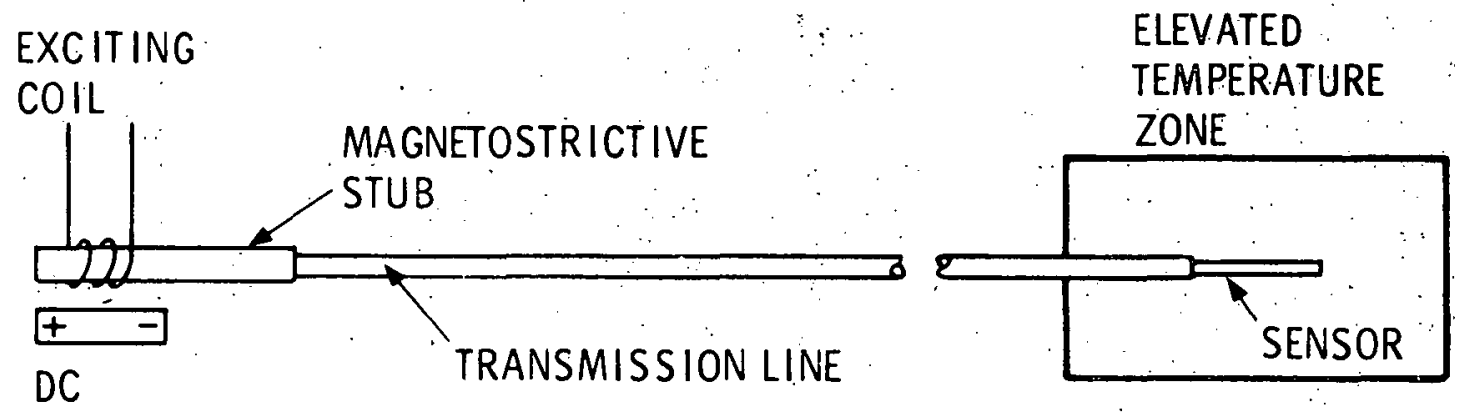

MAGNET

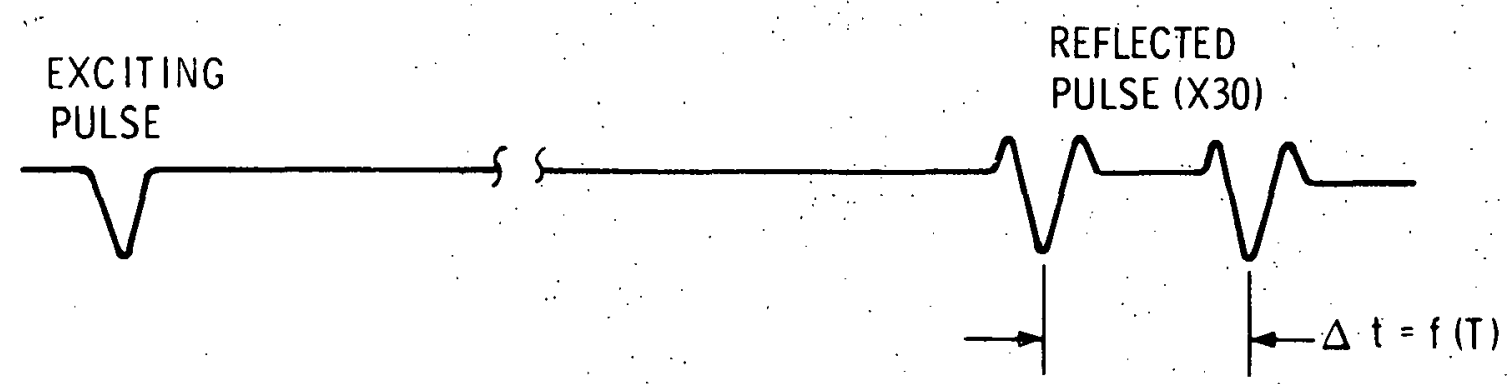

Figure 1. Schematic of an ultrasonic thermometer, showing the exciting coil and dc magnet used to generate and reacquire a signal in the magnetostrictive stub, the transmission line, and the sensor element in an elevated temperature zone. The temperature-dependent delay between the electrical signals generated by the reflected acoustic pulses is shown in Figure lb. 


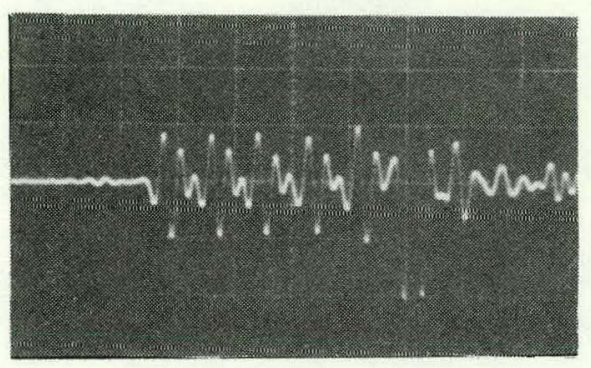

Figure 2. Ultrasonic thermometry signals from five 10-mm length sensor elements of $2 \%$ thoriated tungsten. The acoustic pulse length was chosen to minimize overlap of adjacent reflections while maximizing signal amplitude. 


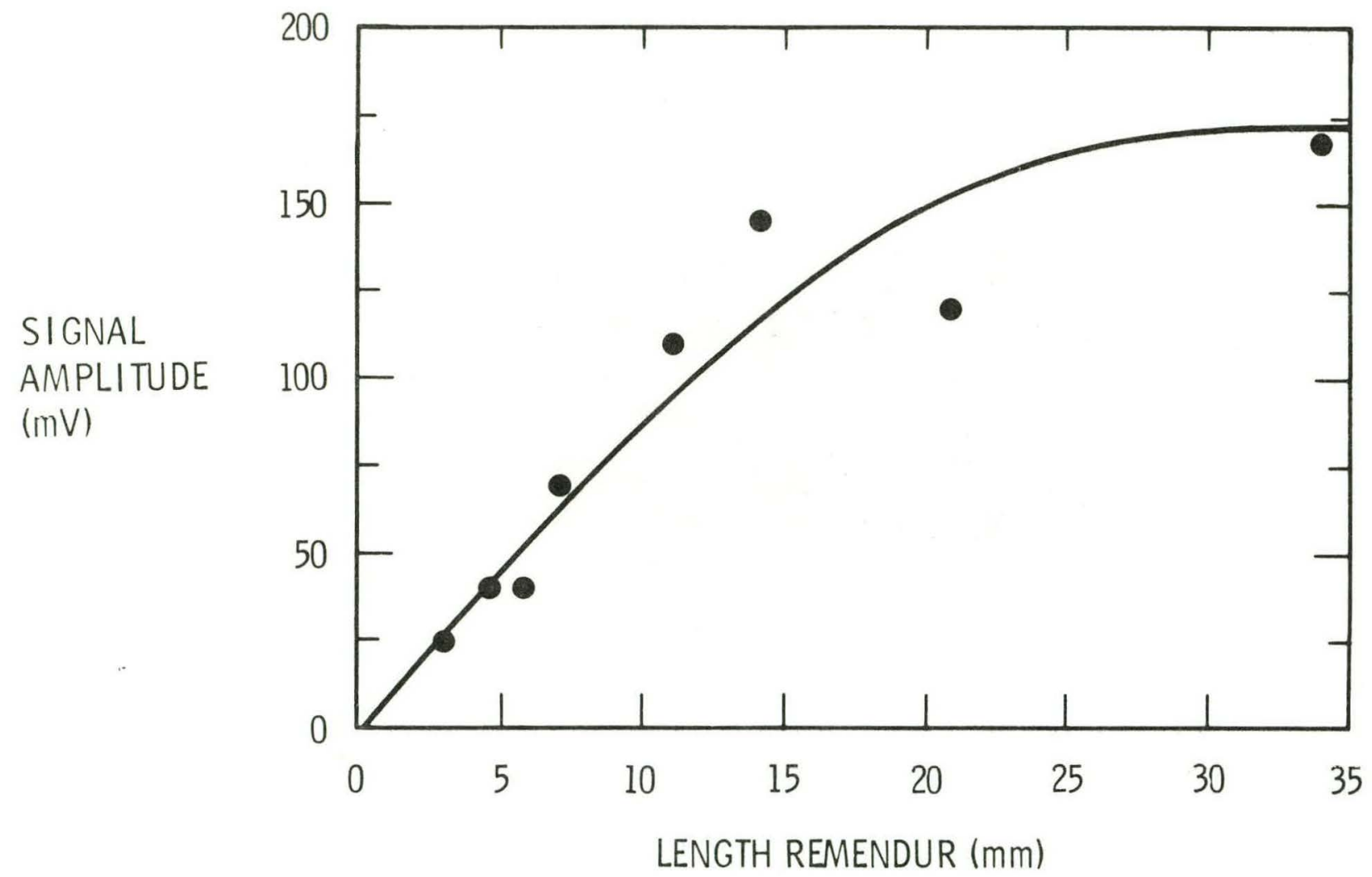

Figure 3. Pulse amplitude as a function of the length of the remendur stub, showing decreased coupling of signals as the remendur length becomes comparable to the length of exciting coil and DC magnet. 


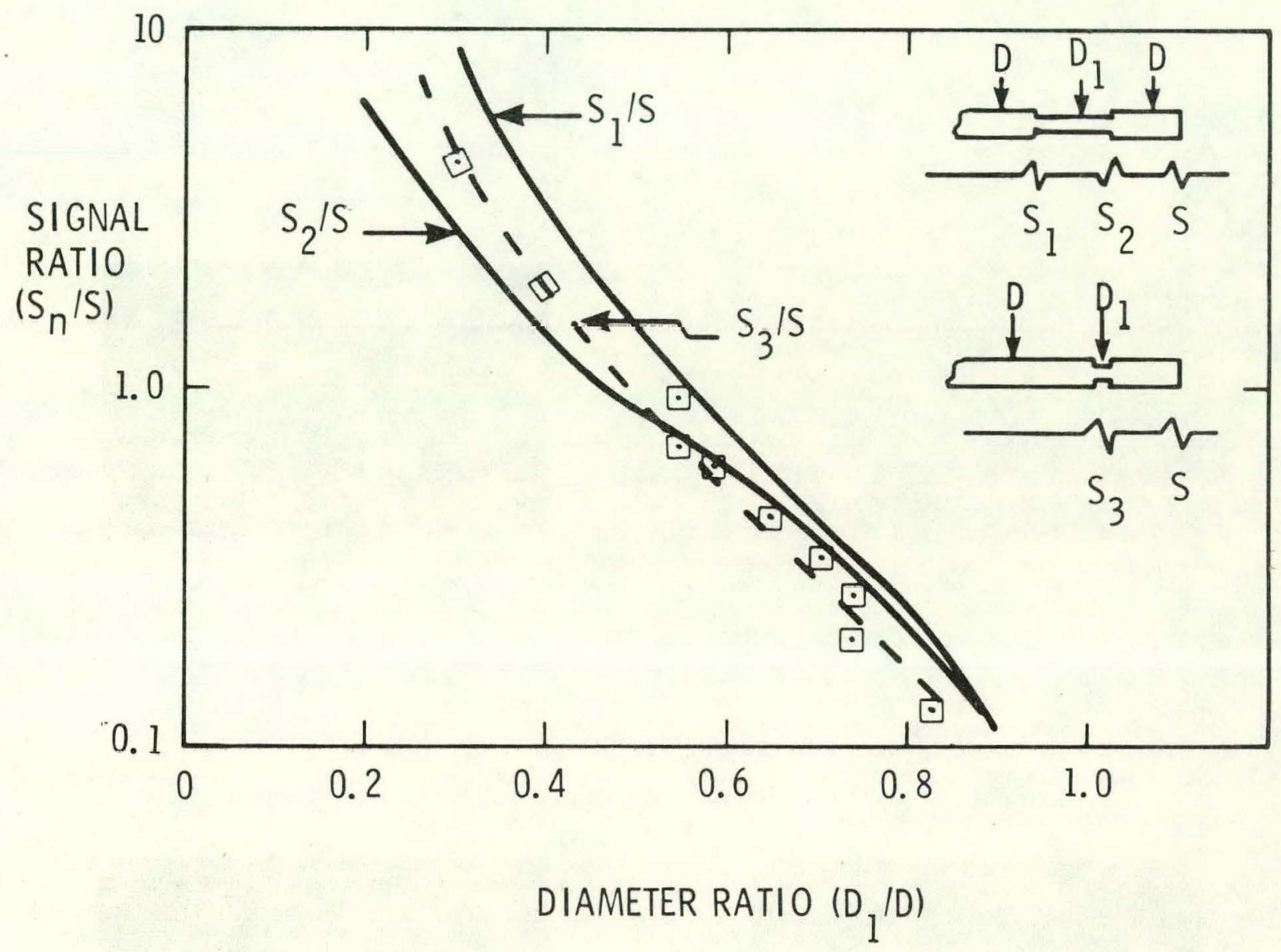

Figure 4. Signal ratio (step or notch signal amplitude to end reflection amplitude) as a function of the ratio of the step or notch depth to the wire diameter. Shown are calculated signal amplitudes from one and two-step diameter changes, $\left(S_{1}\right.$ and $\left.S_{2}\right)$ and measured signal amplitudes from a notch $\left(\mathrm{s}_{3}\right)$. 


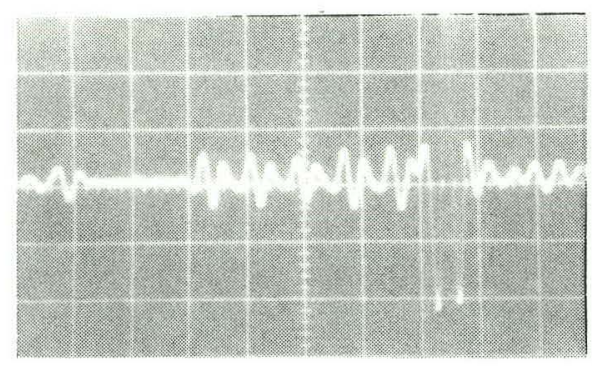

a. $27^{\circ} \mathrm{C}$

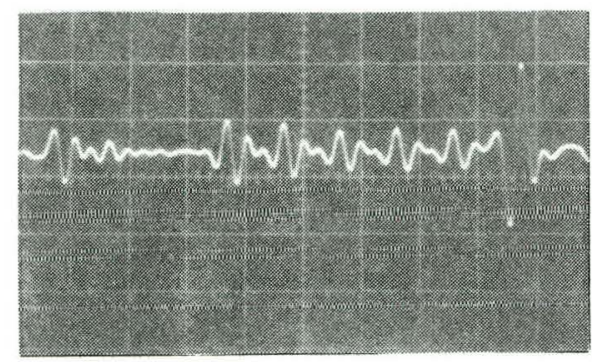

C. $2437^{\circ} \mathrm{C}$

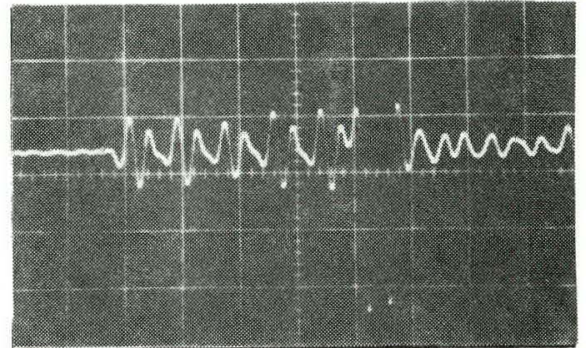

b. $812^{\circ} \mathrm{C}$

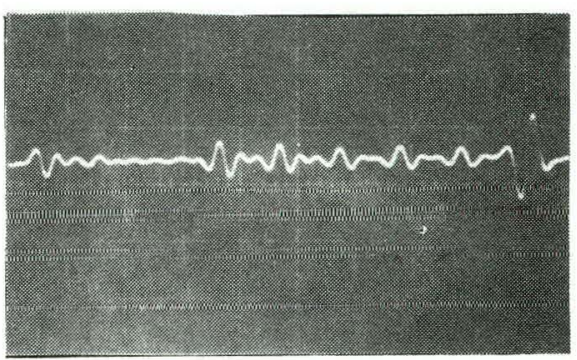

d. $2825^{\circ} \mathrm{C}$

Figure 5. Calibration signals from five 10-mm length 2\% thoriated tungsten sensor elements at various temperatures. 


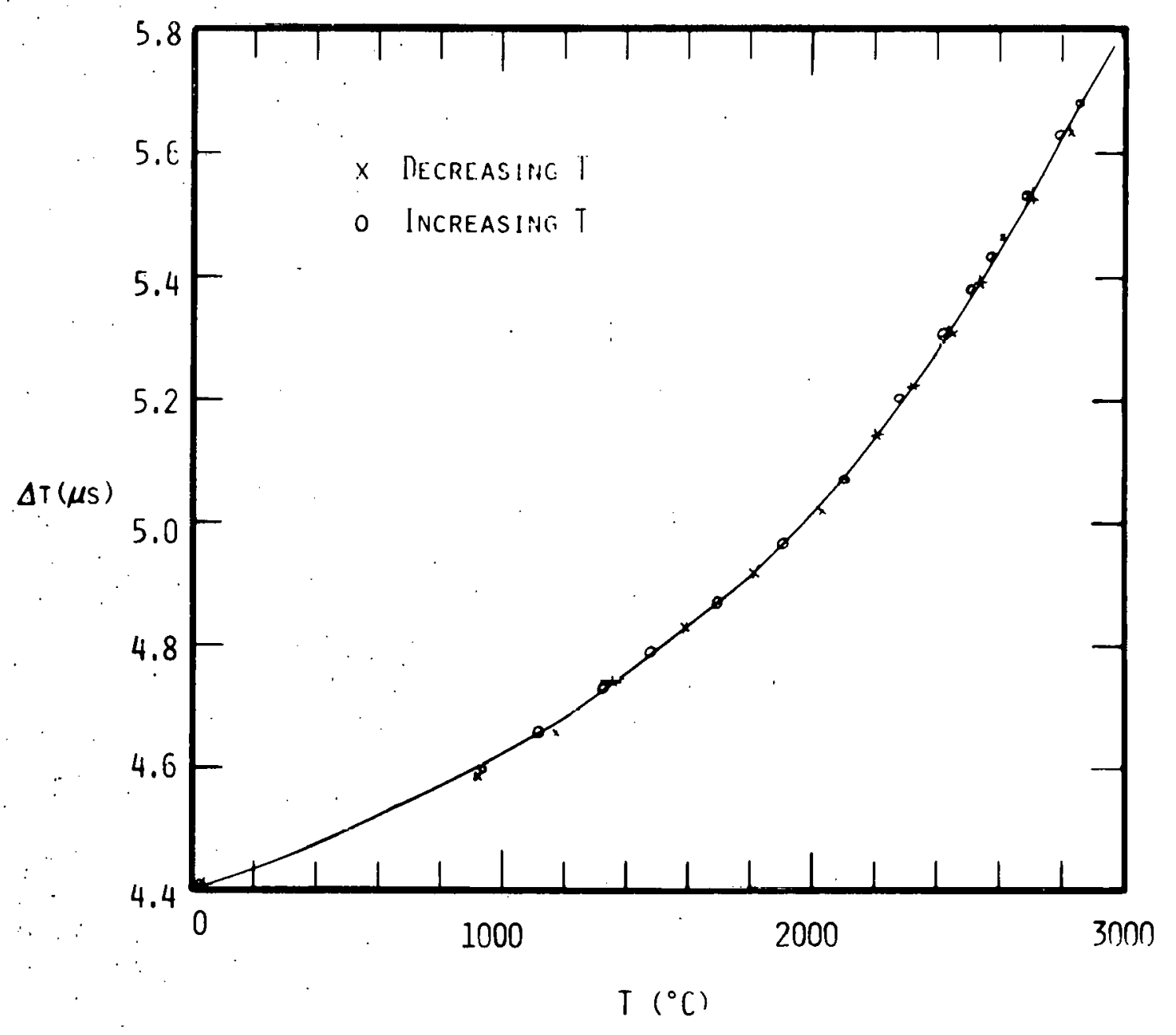

Figure 6. Temperature-delay time calibration curves for a $28-$ thoriated tungsten ultrasonic thermometer. 


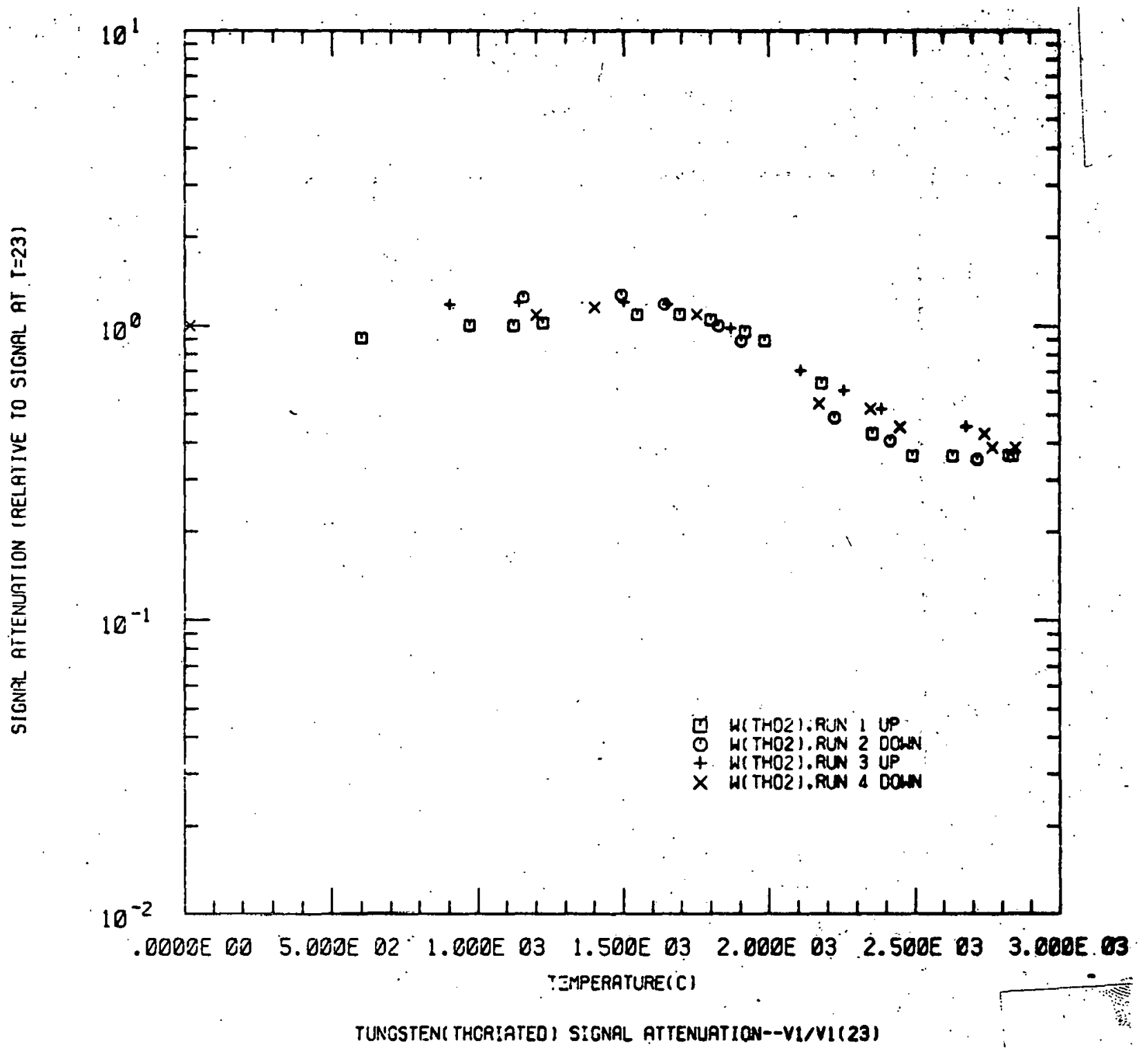

Figure 7. Amplitude of a reflected signal from a 28 thoriated tungsten sensor located $80 \mathrm{~mm}$ into the high temperature zone of a furnace. 


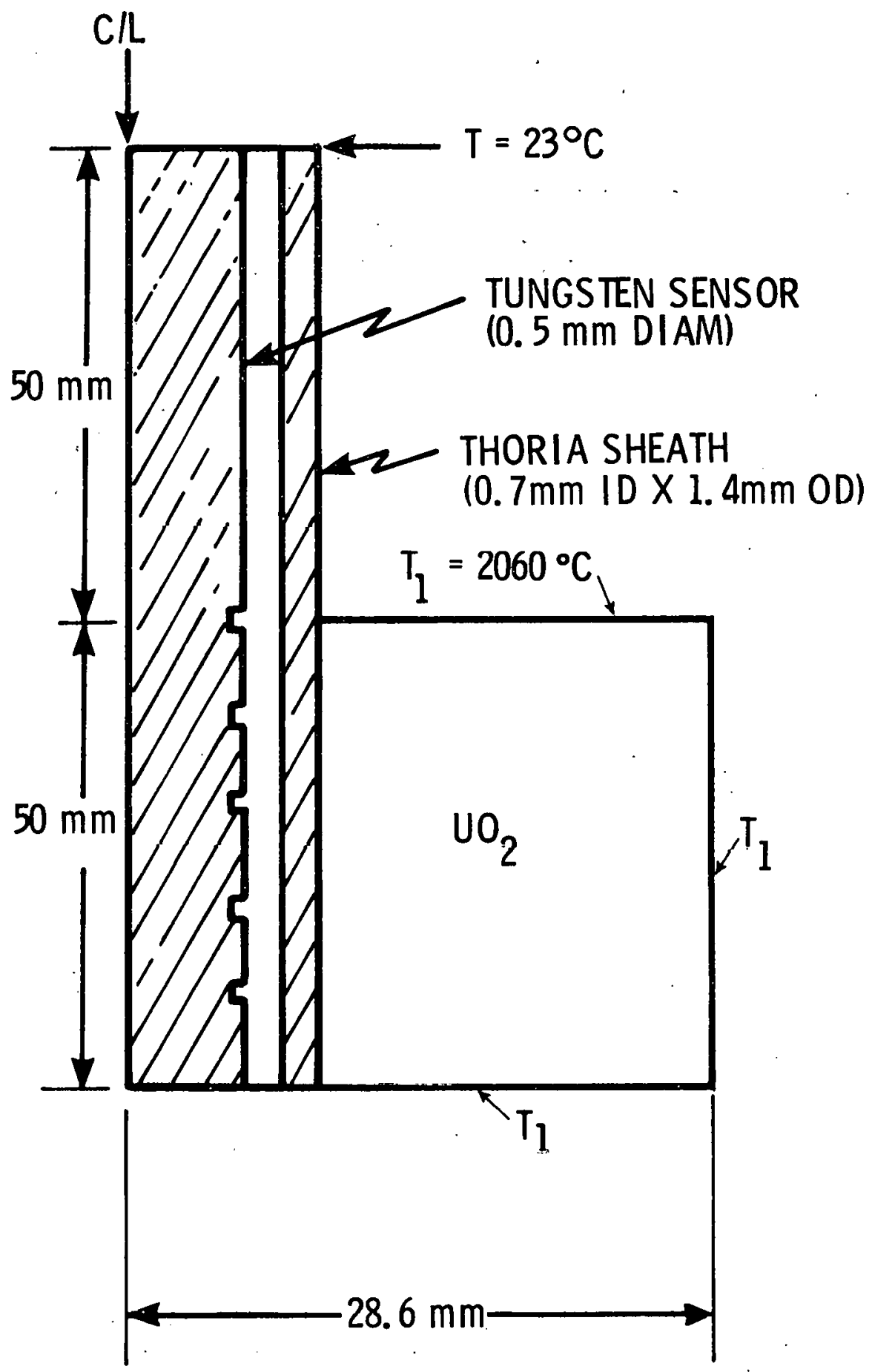

Figure 8. Ultrasonic sensor geometry used in steady-state heat transfer model to define axial heat transfer in sensor wire and sheath and resulting temperature perturbation in $\mathrm{UO}_{2}$ bed. A volumetris energy deposition in the $\mathrm{UO}_{2}$ of $6.5 \mathrm{~W} / \mathrm{Cc}$ gave a maximum $\mathrm{UO}_{2}$ temperature of $2730^{\circ} \mathrm{C} .^{2}$ Thermal conductivities assumed were $0.015 \mathrm{~W} / \mathrm{cmK}\left(\mathrm{UO}_{2}\right)$, $0.02 .4 \mathrm{~W} / \mathrm{cmK}\left(\mathrm{ThO}_{2}\right)$, and $1.0 \mathrm{~W} / \mathrm{cmK}$ (Tungsten). 


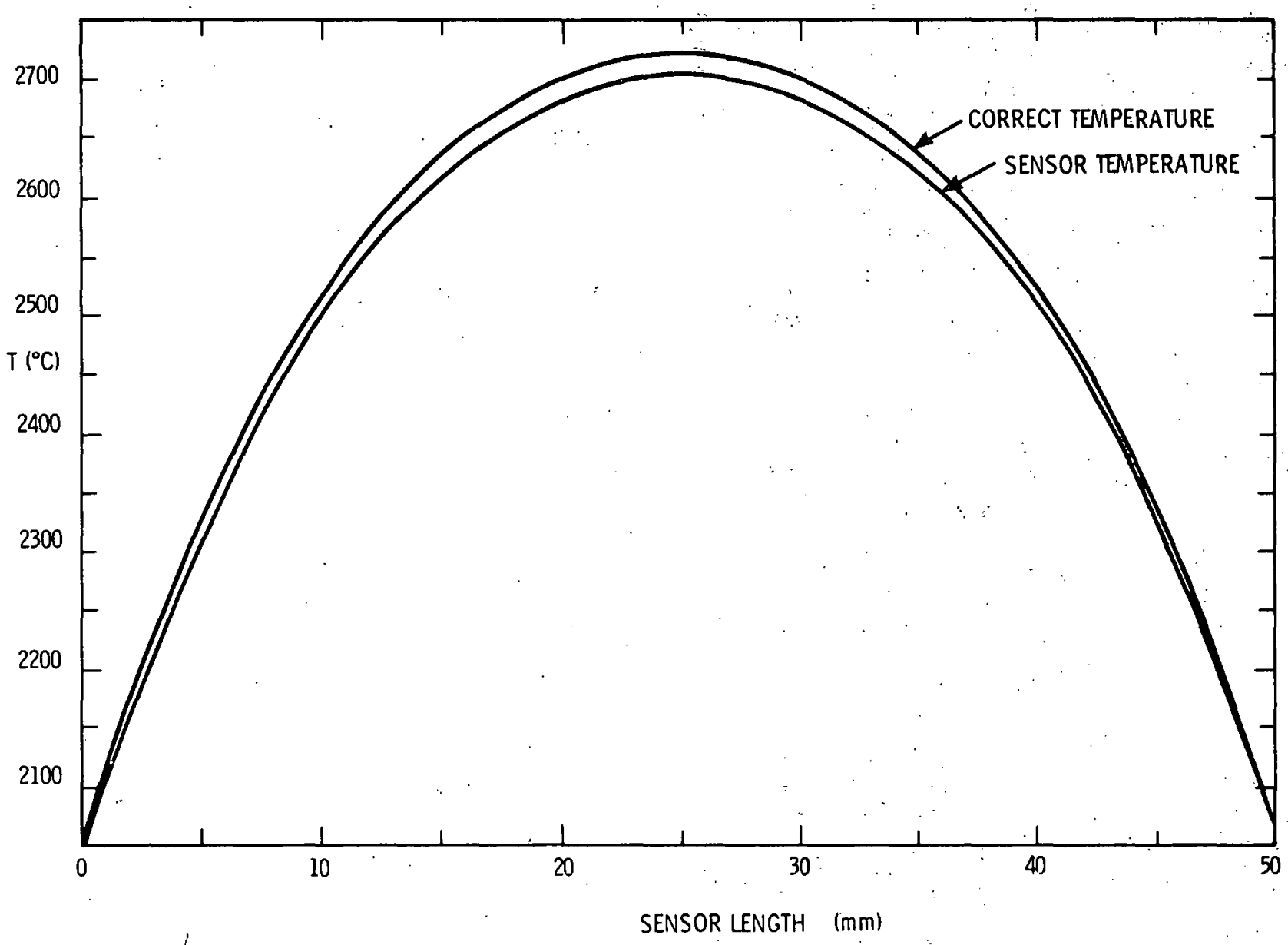

Figure 9. Temperature gradients in a volumetrically heated $\mathrm{UO}_{2}$ bed, with and without a $\mathrm{ThO}_{2}$-sheathed ultrasonic thermometer present, calculated using the steadystate model and the geometry shown in Figure 8 . 

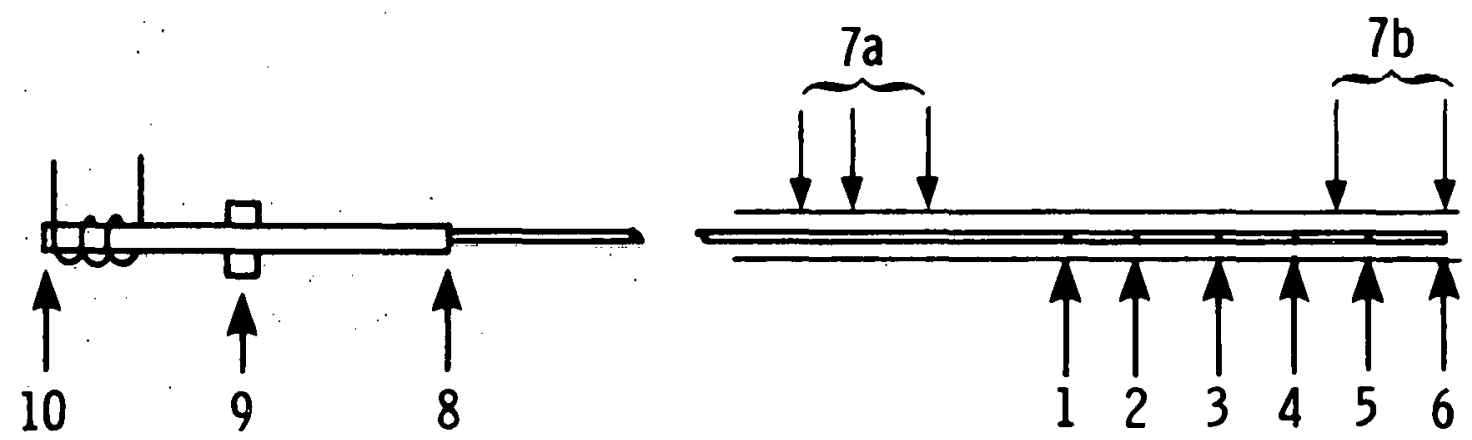

Figure 10. Schematic of ultrasonic thermometer showing normal sensor element reflections $(1-6)$, plus unwanted, potentially interfering reflections at vacuum feedthrough (9), remendur-tungsten weld (8) and sheath-sensor contact points $(7 a, 7 b)$. 


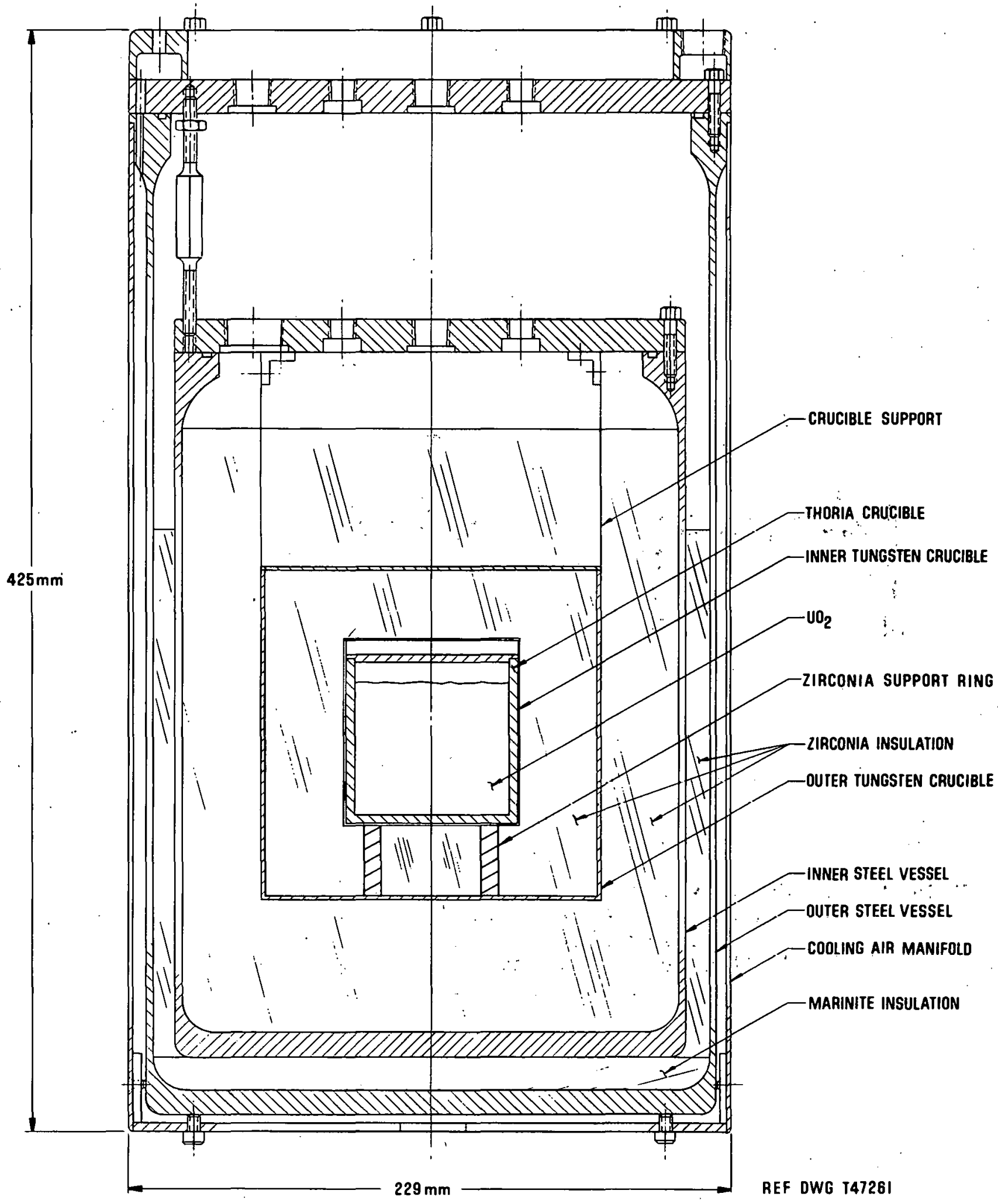

Figure 11. Cross-sectional view of small capsule fuel-only experiment package. 


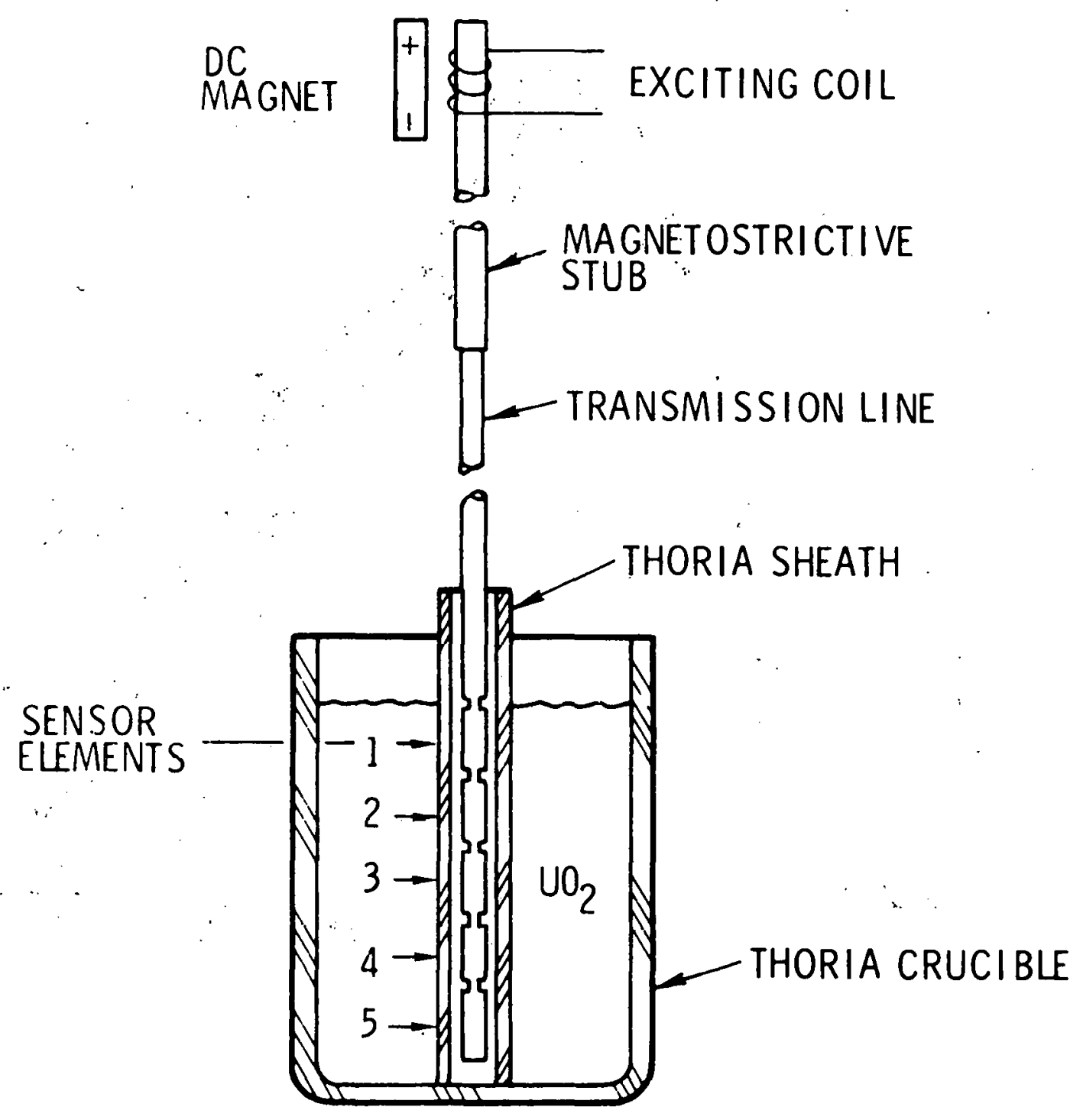

Figure 12. Five-element ultrasonic thermometer in $\mathrm{UO}_{2}$ (sche-
matic-not to scale). 


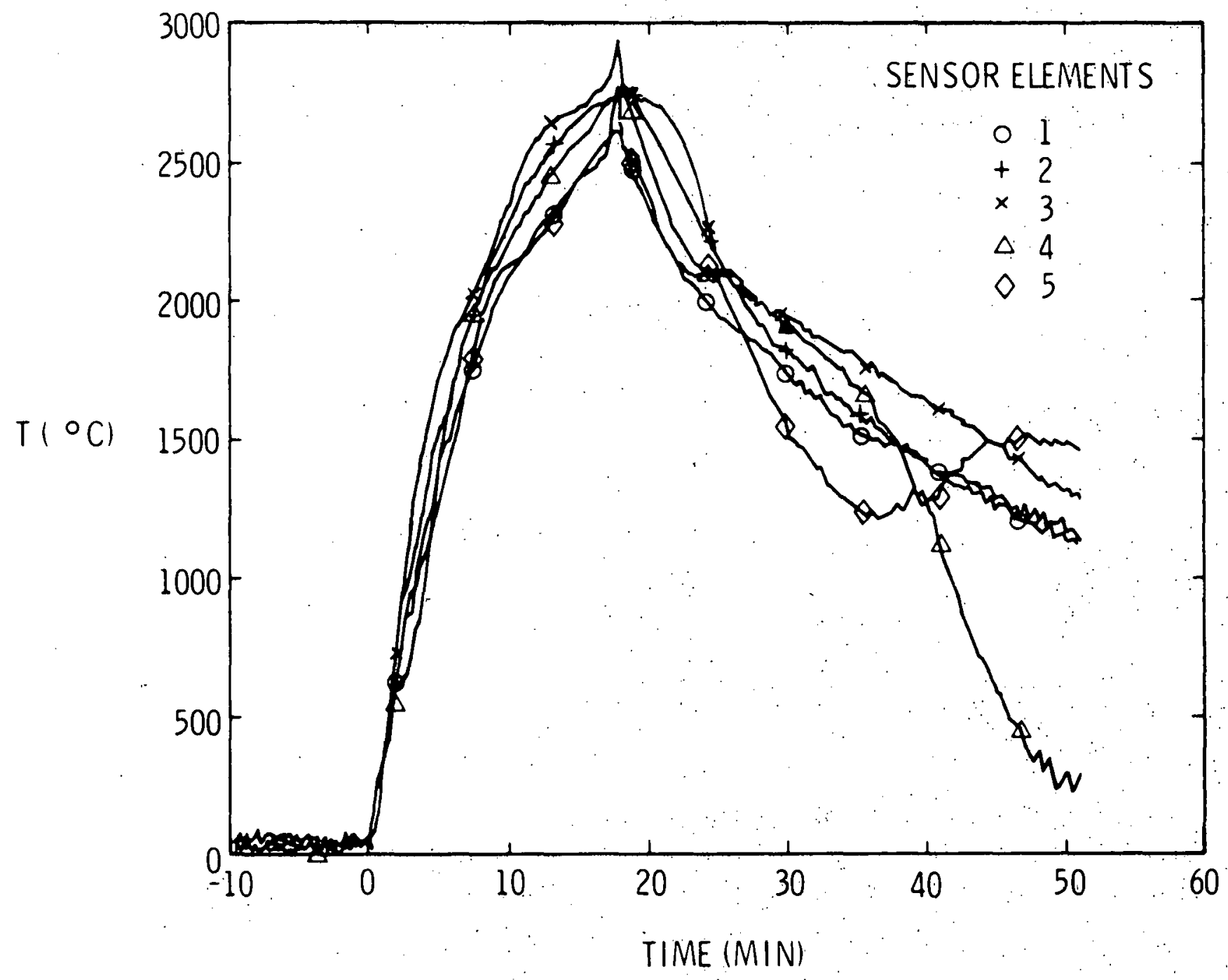

Figure 13. Axial temperatures for first in-core fuel-only experiment, MP-1, recorded by ultrasonic thermometry. 


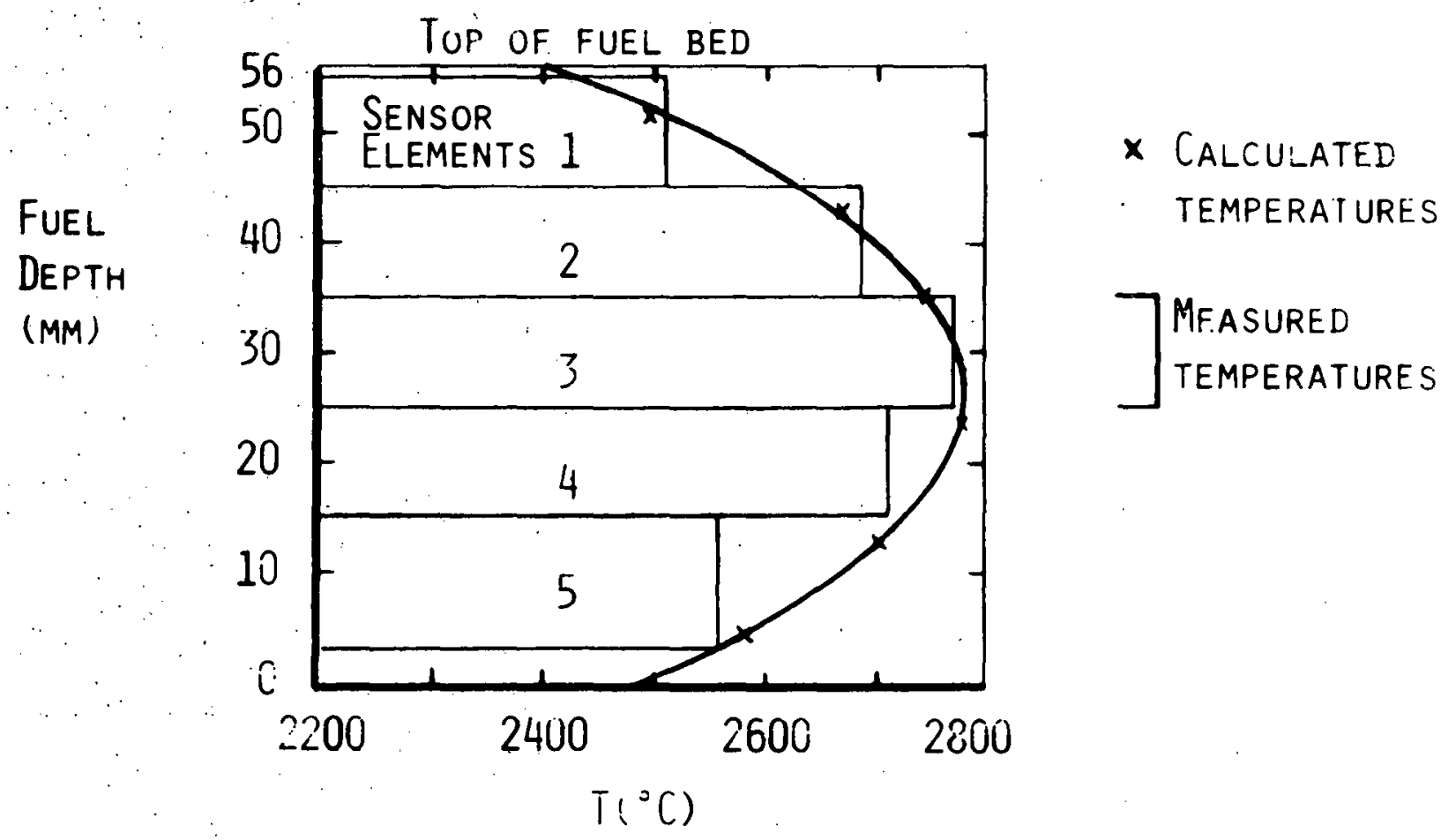

Figure 14. Temperature profile data in MP-1 near end of powered portion of experiment. 


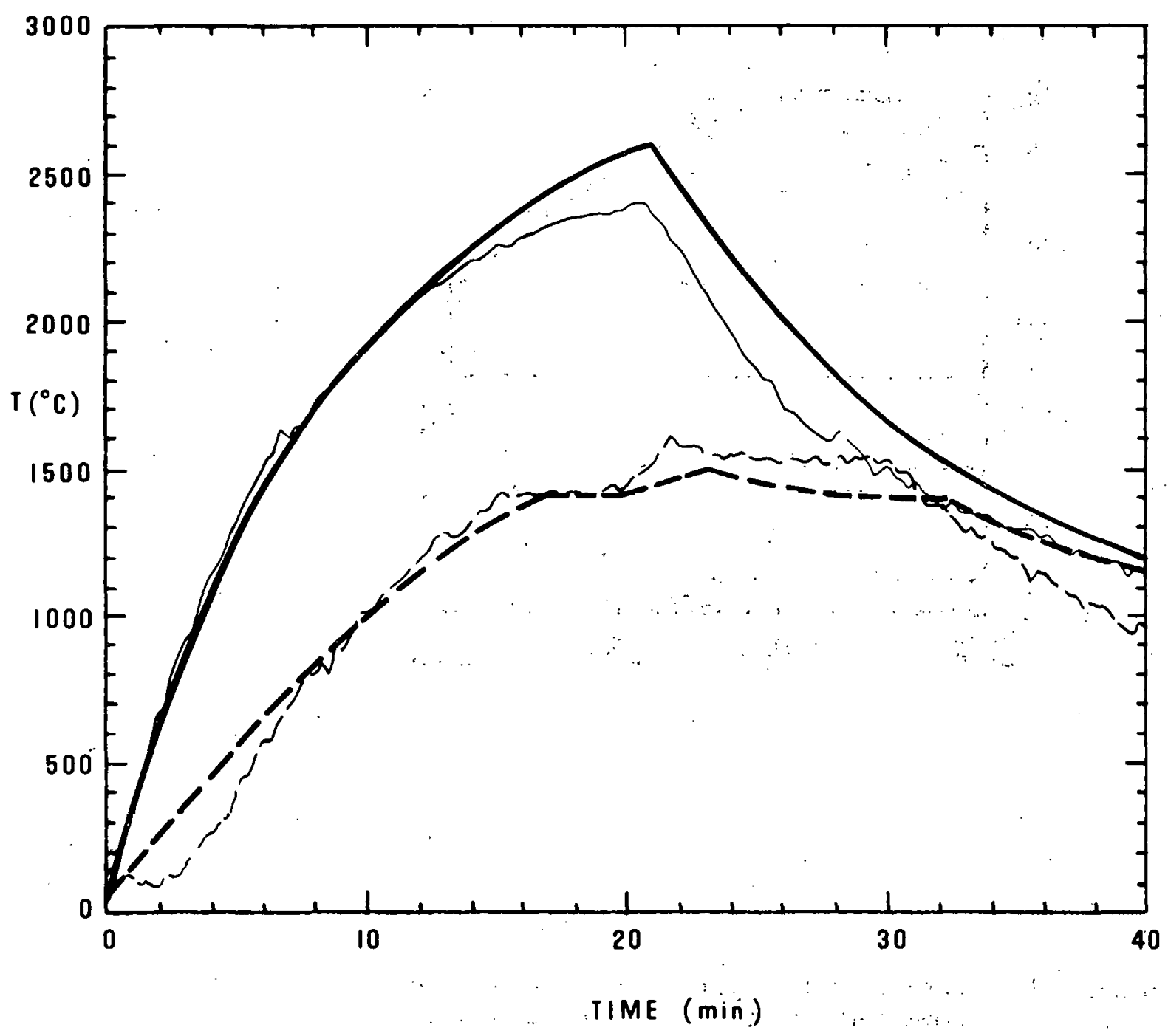

Figure 15. Temperature data for first in-core fuel-steel experiment, MP-3S, recorded by ultrasonic thermometry. Solid lines are maximum fuel temperature, dashed lines are steel temperature. Bold lines are calculated, light 1 ines experimentally measured temperatures. 

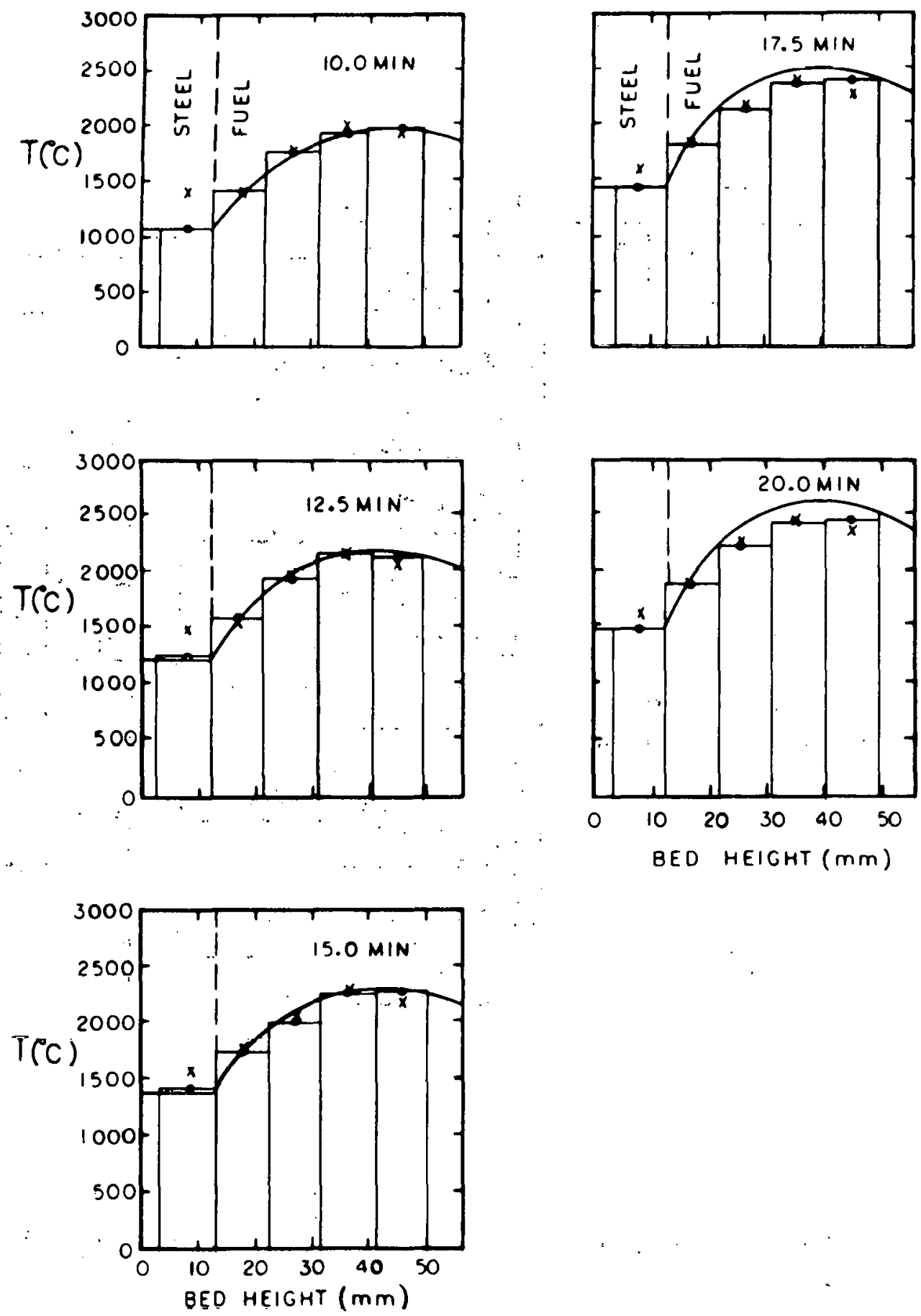

Figure 16. Comparison of measured and calculated temperatures during MP-33. Solid lines are calculations; $x$ and - are ultrasonic thermometry data from the two sensors. 


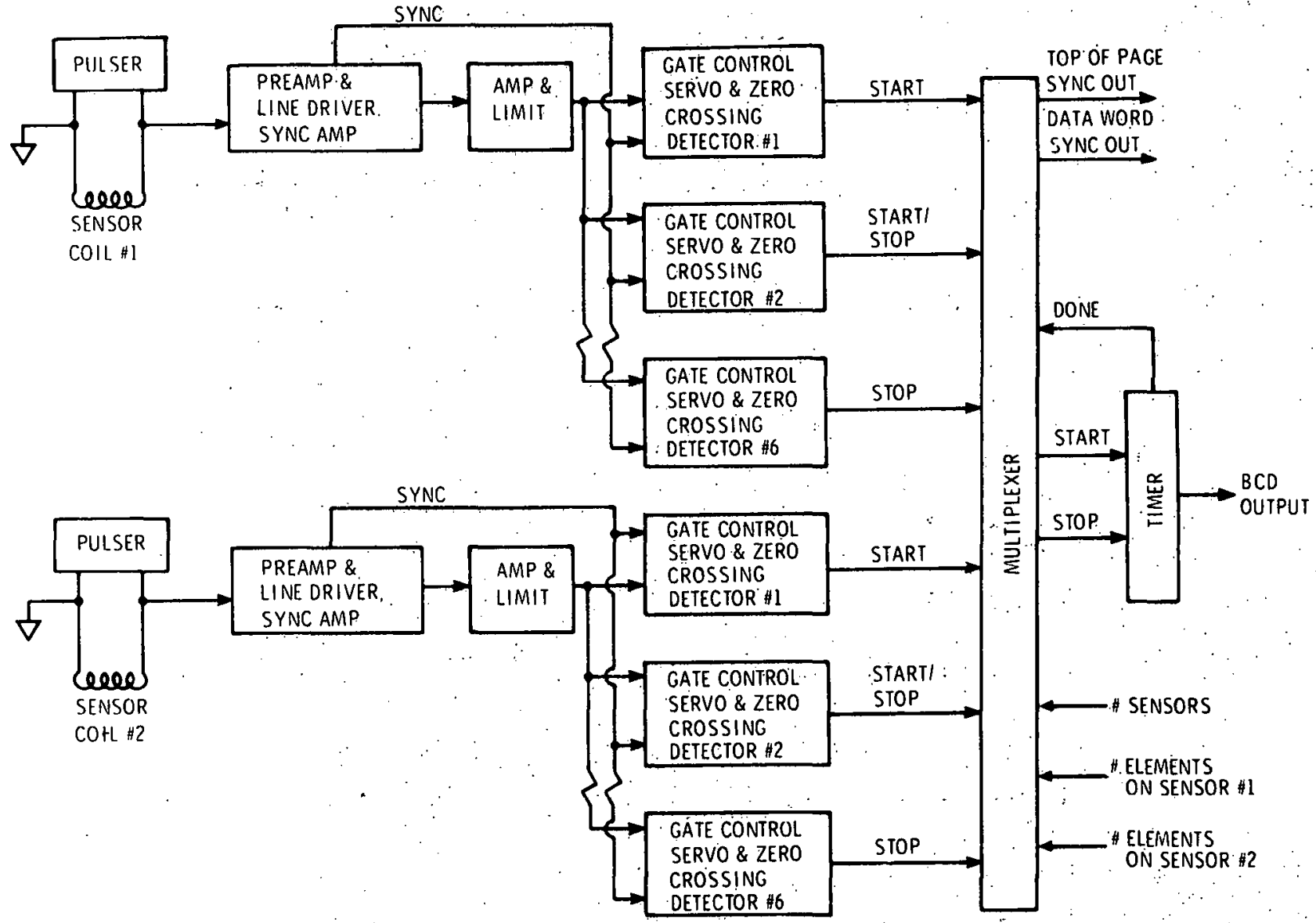

Figure Al Ultrasonic thermometry electronics control--block di agram. 


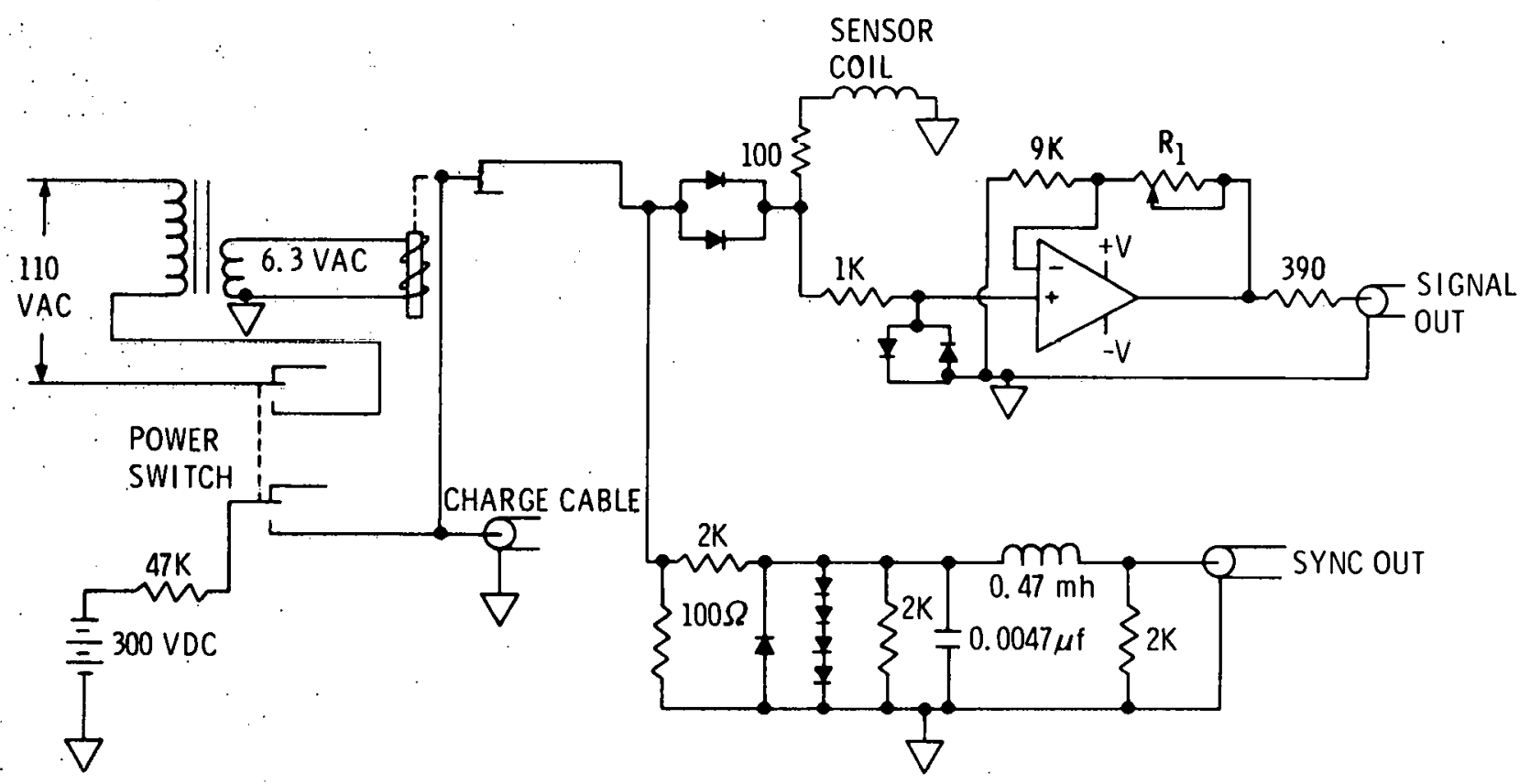

NOTE: ALL DIODES FD-100

PRE-AMP: BURR-BROWN 3400B

RELAY: CLARE HGSMIO09

$\mathrm{R}_{1}=20 \mathrm{~K}$ TRIMPOT

Figure A2 Coil pulser, signal preamp and sync signal generator-schematic. 


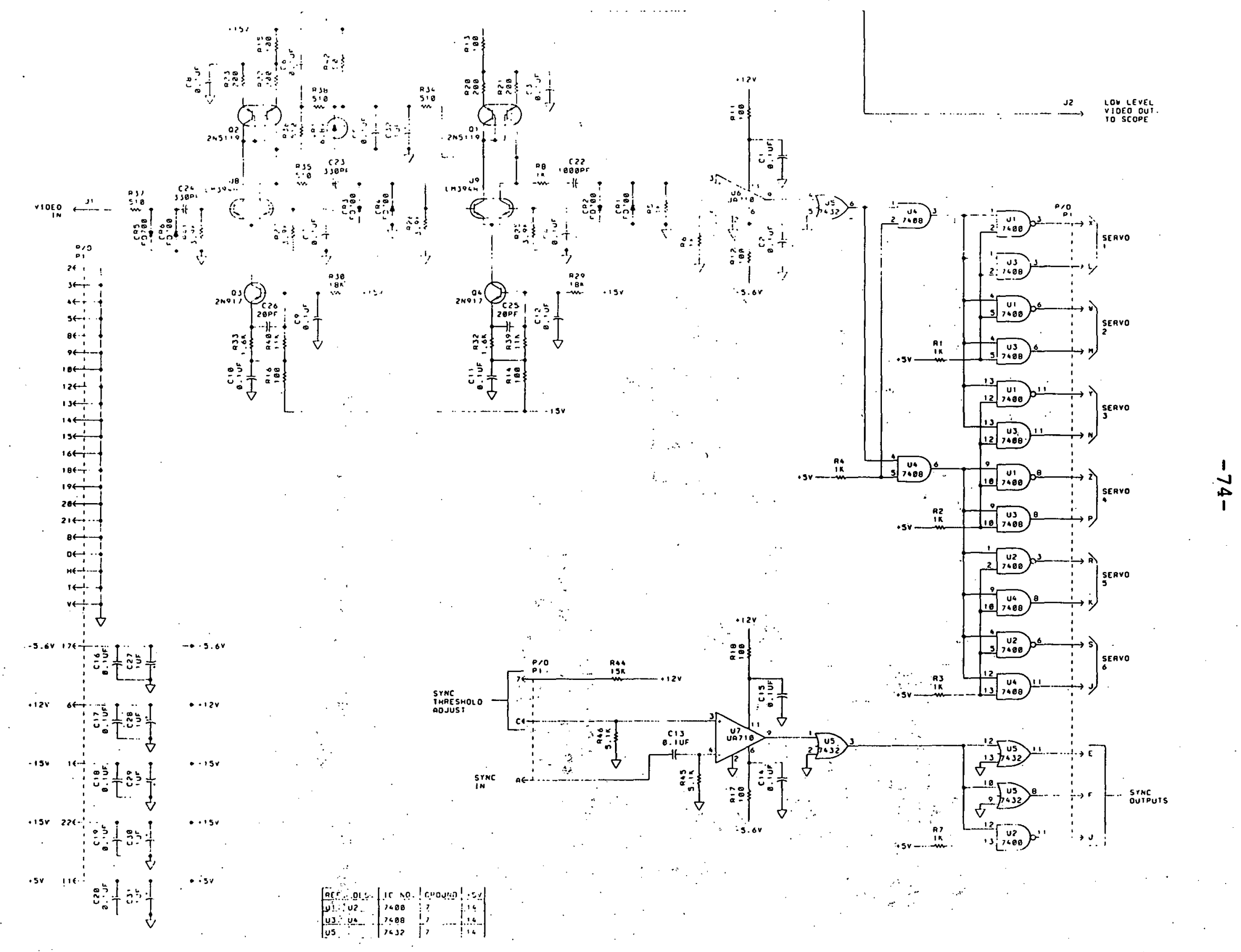

Figure $A 3$ Video and sync amplifiers--schematic. 


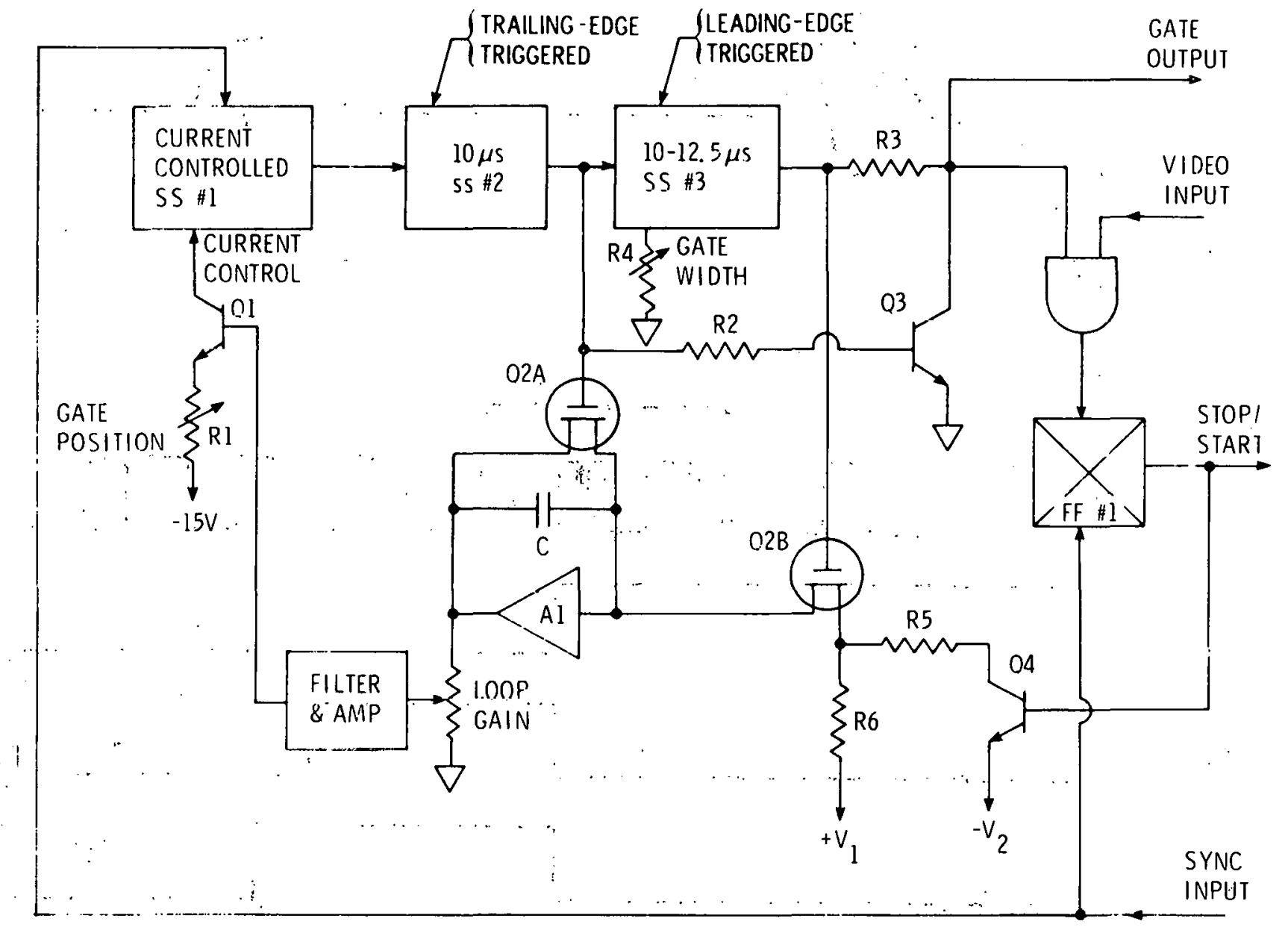

Figure A4 Signal outputs of control electronics--aiagrammatic representation. 


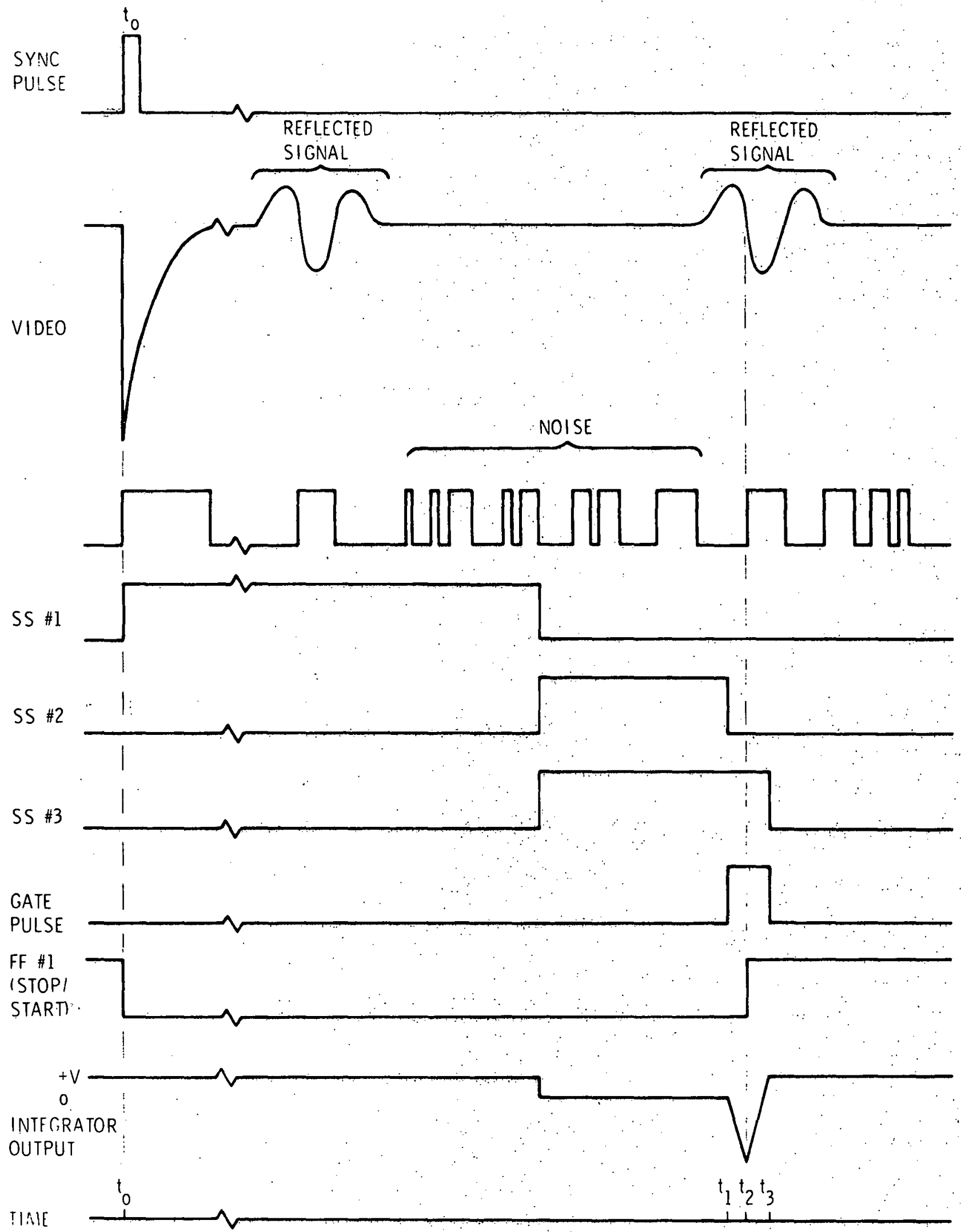

Figure A5 Signal outputs of control electronics--diagrammatic representation.: 


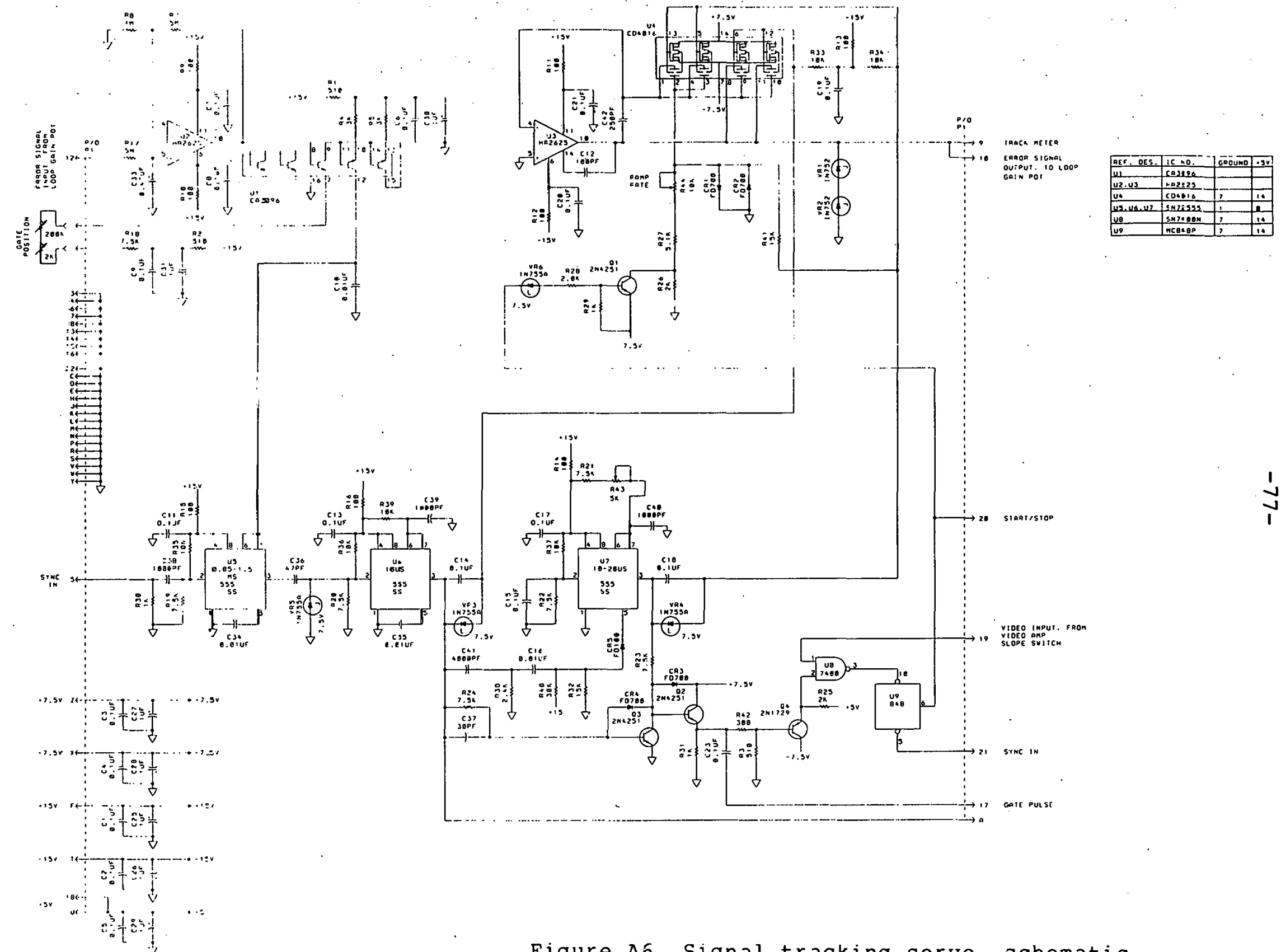

Figure Á́ Signal tracking servo--schematic. 


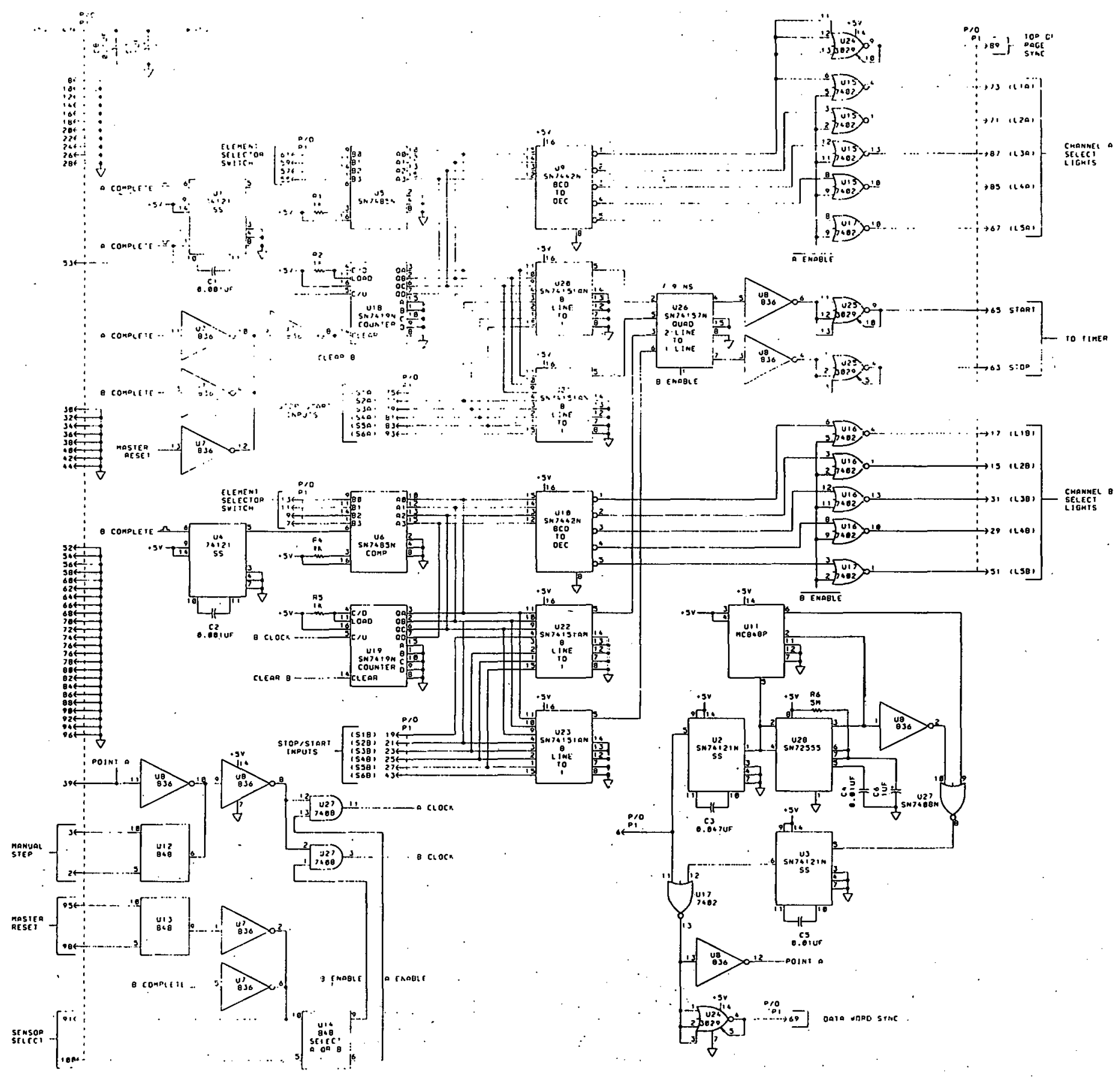


(a)

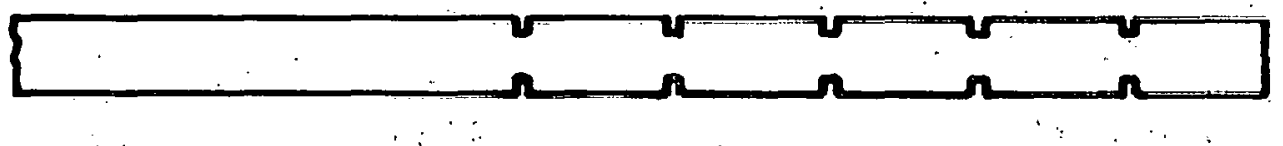

(b)

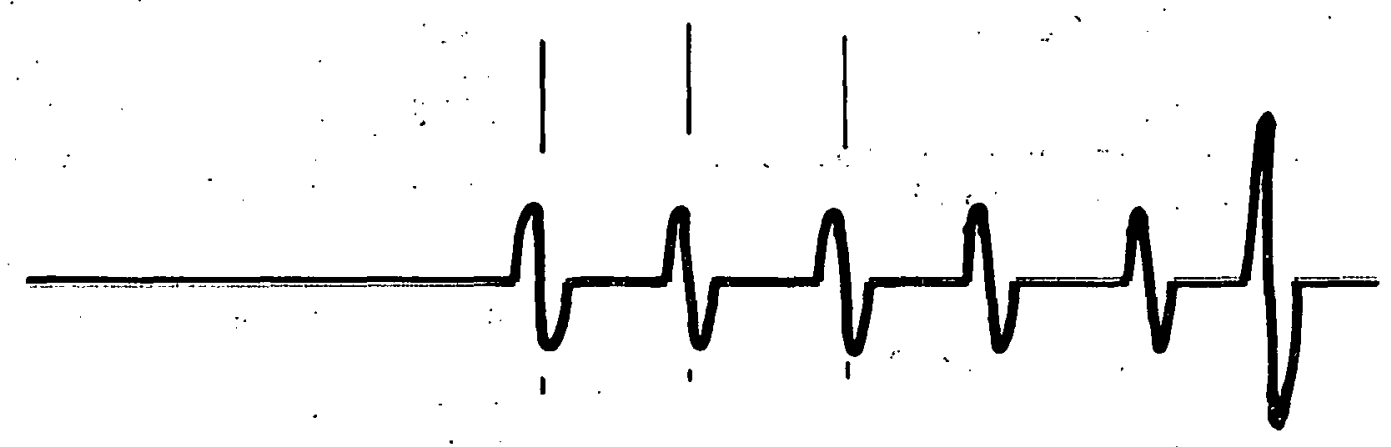

(c)
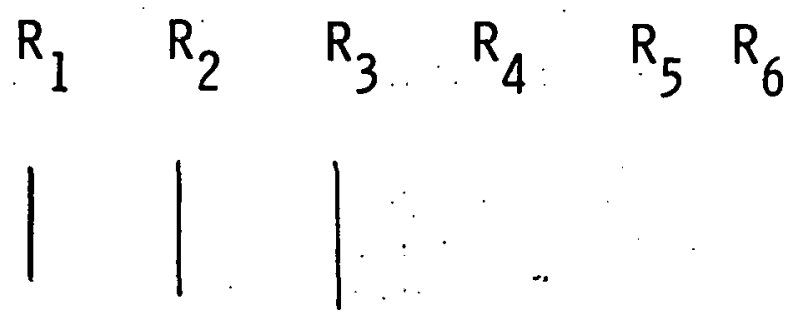

(d)

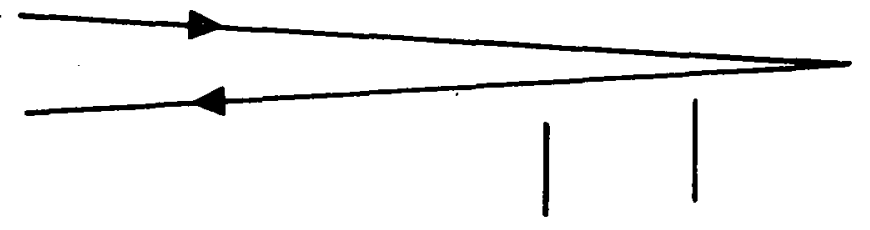

REFLECTION PATH $\mathrm{R}_{3}$

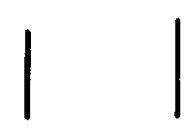

REFLECTION PATH :$\mathrm{R}_{212}$

Figure Bl Diagrammatic representation of a) five-element ultrasonic thermometer, b) primary reflected signals from. thermometer, c) path of primary reflection $R_{3}$, and d) path of secondary reflected signal $R_{212}$, which overlaps $\mathrm{R}_{3}$. 
Distribution:

USNRC ( 285 copies for R-7)

$442: 2$

Div. of Document Control

4.423

Bethesda, MD 20014

4423

L. C. Lyinnworth

44.24

4425

Panametrics, Inc.

Waltham, MA 02154

4430

4450

4451

R. L. Shepard

Oak Ridge National Laboratory

4452

4453

Oak Ridge, TN 37830

A. E. Arave

583.1

EG\&G

5842

Idaho Falls, ID 83401

3141

3151

R. H. Meservey

8266

EG\&G

$3172-3$

D. W. Varela

J. E. Powell

W. H. Sullivan

P. S. Pickard

W. J. Camp

R. M. Jefferson

J. A. Reuscher

T. R. Schmidt

L. D. Posey

W. J. Whitfield

H. M. Stoller,

Attn: C. L. Schuster, 4733

Idaho Falls, ID :83401.

D. A. Powers

J. N. Sweet

T. L. Werner

W. L. Garner

E. A. Aas

H. E. Schmidt

European Institute for Transuranium Elements

75 Karlsruhe, Postfach 2266

Germany

H. Hohmann

JRC - Ispra, Ed. 42

I-21020 ISPRA

Italy

L. Baker

Argonne National Laboratory

Argonne, IL 60439

R. Grossman

Knolls Atomic Laboratory

Schenectady, NY 12301

$\begin{array}{ll}1537 & \text { T. Y. Chu } \\ 1552 & \text { J. H. Gieske } \\ 2151 & \text { R. C. Heckman } \\ 2151 & \text { G. A Carlson } \\ 4000 & \text { A. Narath } \\ 4400 & \text { A. W. Snyder } \\ 4410 & \text { D. J. McCloskey } \\ 4420 & \text { J. V. Walker } \\ 4422 & \text { R. L. Coats } \\ 4422 & \text { R. M. Elrick } \\ 4422 & \text { J. M. Gronager } \\ 4422 & \text { T. M. Kerley } \\ 4422 & \text { J. B. Rivard }\end{array}$

R. P. Campbell

for DOE/TIC

Unlimited Release 作 


\section{DO NOT MICROFILM COVER}

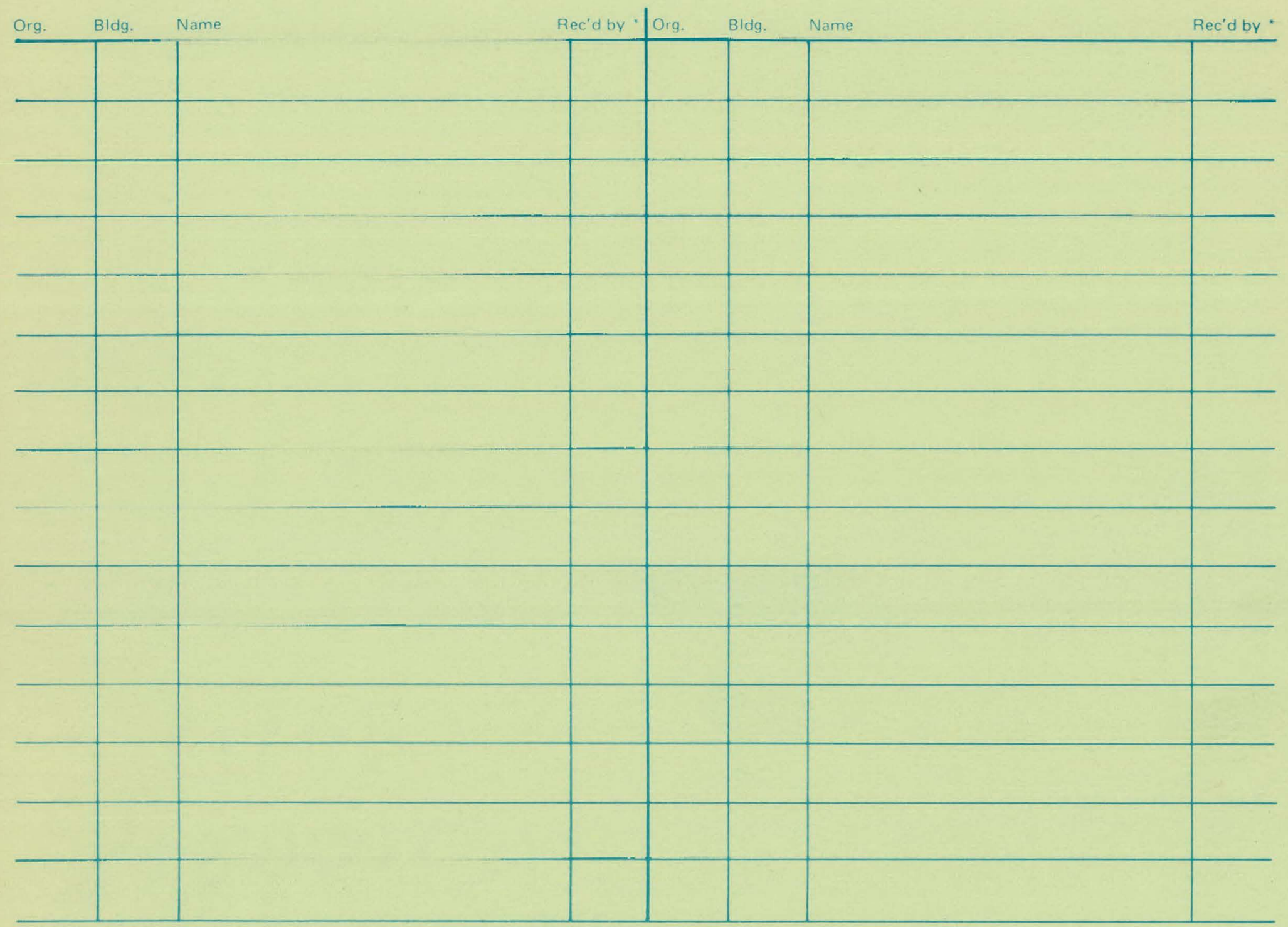

- Recipient must initial on classified documents. 